\title{
Functionalized Polyesters via Stereoselective Electrochemical Ring-Opening Polymerization of $O$-Carboxyanhydrides
}

\author{
Yongliang Zhong, ${ }^{\dagger}$ Quanyou Feng, ${ }^{\dagger, \dagger}$ Xiaoqian Wang, ${ }^{\dagger}$ Jia Chen, ${ }^{\S}$ Wenjun Cai, ${ }^{\S}$ Rong Tong ${ }^{\dagger, *}$ \\ $\dagger$ Department of Chemical Engineering, Virginia Polytechnic Institute and State University, 635 Prices Fork Road, \\ Blacksburg, Virginia, 24061, United States. \\ \$ Key Laboratory for Organic Electronics and Information Displays, Jiangsu Key Laboratory for Biosensors, \\ Institute of Advanced Materials, Jiangsu National Synergetic Innovation Center for Advanced Materials, Nanjing \\ University of Posts and Telecommunications, 9 Wenyuan Road, Nanjing, 210023, China. \\ $\S$ Department of Materials Science and Engineering, Virginia Polytechnic Institute and State University, 400 \\ Stanger Street, Blacksburg, Virginia, 24061, United States. \\ *Correspondence to: rtong@vt.edu
}

\section{Supplementary information}




\section{Table of Contents}

$\begin{array}{ll}\text { S1. Materials } & \text { S-3 }\end{array}$

S2. Instrument and Characterization $\quad$ S-5

S3. Polymerization Procedures $\quad$ S-7

S4. Tables S1-9 S-11

S5. Figures S1-21 S-24

S6. References $\quad$ S-53 


\section{S1. Materials}

\section{S1.1 General}

Bis(1,5-cyclooctadiene) nickel(0) (Ni(COD) $)$, 2,2'-bipyridine (bpy), bis[2-(2,4-difluorophenyl)5-(trifluoromethyl)pyridine] iridium(III)

hexafluorophosphate

(Ir-1), chlorotris(triphenylphosphine) cobalt(I), (1R,2R)-(-)-1,2-cyclohexanediamino- $N, N$ '-bis(3,5-di-tbutylsalicylidene) cobalt(II), cyclopentadienylcobalt dicarbonyl, dichloro[1,1'bis(diphenylphosphino)ferrocene]cobalt(II), cobalt(II) dibromo(1,2-dimethoxyethane), anhydrous cobalt(II) chloride and meso-tetraphenylporphyrin cobalt(II) were purchased from Strem Chemicals (Newburyport, MA). $O$-benzyl-L-serine, $O$-benzyl-D-serine, L-glutamic acid- $\gamma$ benzyl ester and D-glutamic acid- $\gamma$-benzyl ester were purchased from Chem-Impex (Wood Dale, IL). L-phenylalanine and D-phenylalanine was purchased from Alfa Aesar (Haverhill, MA). Anhydrous tetrahydrofuran (THF) was dried by alumina columns and stored with $4 \AA$ molecular sieve in the dark bottle in the glove box. Anhydrous THF- $d_{8}$, benzyl alcohol, hexane, benzene, toluene, diethyl ether, diisopropyl ether, pyridine and dichloromethane were dried and stored by $4 \AA$ molecular sieves in the glove box. All other chemicals were purchased from Sigma-Aldrich (St. Louis, MO) unless otherwise noted.

\section{S1.2 OCA monomers}

L-PheOCA (L-1) and D-PheOCA (D-1), ${ }^{1}$ L-Ser(Bn)OCA (L-2) and D-Ser(Bn)OCA (D-2), ${ }^{2}$ LGlu(Cbz)OCA (L-3) and D-Glu(Cbz)OCA (D-3), ${ }^{3}$ L-LacOCA (L-4) and D-LacOCA (D-4), ${ }^{4}$ and LManOCA (L-5) and D-ManOCA (D-5), ${ }^{5}$ were synthesized and recrystallized according to the literature. All OCA monomers were recrystallized three times and stored in $-30{ }^{\circ} \mathrm{C}$ freezer in the glove box.

\section{S1.3 Zn complexes}

$\mathrm{Zn}(\mathrm{HMDS})_{2} \quad$ (Zn-1) was prepared and distilled according to the literature. ${ }^{6}$ (NNO1) $\mathrm{ZnN}\left(\mathrm{SiMe}_{3}\right)_{2}(\mathbf{Z n - 2})$ was prepared following the literatures. ${ }^{7} \beta$-diiminate $\mathrm{Zn}$ complexes $(\mathbf{Z n - 3})$ were synthesized according to the literature. ${ }^{8}$ All $\mathrm{Zn}$ complex were stored in the glove box freezer $\left(-30^{\circ} \mathrm{C}\right)$.

\section{S1.4 Ni complex}

The $\mathrm{Ni}$ complex solution was prepared freshly prior to the reaction. In a glove box, $\mathrm{Ni}(\mathrm{COD})_{2}$ (5.5 mg, $0.02 \mathrm{mmol}$ ) was mixed with bipyridyl ligand (e.g., bpy, $3.1 \mathrm{mg}, 0.02 \mathrm{mmol}$ ) or or 
tricyclophosphine $(11.2 \mathrm{mg}, 0.04 \mathrm{mmol})$ in $\mathrm{THF}$ solution $(300 \mu \mathrm{L})$ at room temperature and stirred for 1-2 hour to ensure all $\mathrm{Ni}(\mathrm{COD})_{2}$ dissolved. The Ni complex solution could be stored in the glove box freezer $\left(-30{ }^{\circ} \mathrm{C}\right)$ no longer than seven days.

\section{S1.5 Co(II) complexes}

$\mathrm{Co}(\mathrm{HMDS})_{2}$ was prepared and distilled according to the literature. ${ }^{9}$ The $\mathrm{Co}(\mathrm{II})$ complexes were prepared freshly prior to the polymerization. In general, $\mathrm{Co}(\mathrm{HMDS})_{2}(2.9 \mathrm{mg}, 7.6 \mu \mathrm{mol})$ was mixed with the ligand (e.g., bpy, $1.2 \mathrm{mg}, 7.6 \mu \mathrm{mol}$, or other phosphine ligand at same equivalent) in toluene solution $(1 \mathrm{~mL})$ at room temperature and stirred for 2 hours to ensure all Co(HMDS $)_{2}$ dissolved. The Co complex solution could be stored in the glove box freezer $\left(-30{ }^{\circ} \mathrm{C}\right)$ no longer than seven days.

\section{S1.5.1 Synthesis of Co-1}

In a glove box, $\mathrm{Co}(\mathrm{HMDS})_{2}(2.9 \mathrm{mg}, 7.6 \mu \mathrm{mol})$ was mixed with the bpy $(1.2 \mathrm{mg}, 7.6 \mu \mathrm{mol})$ in toluene solution $(1 \mathrm{~mL})$ at room temperature and stirred for 2 hours to ensure all $\mathrm{Co}(\mathrm{HMDS})_{2}$ dissolved. The Co-1 complex solution could be stored in the glove box freezer $\left(-30{ }^{\circ} \mathrm{C}\right)$ no longer than seven days.

\section{S1.5.2 Synthesis of Co-2}

In a glove box, $5.0 \mathrm{mg}(5.1 \mu \mathrm{L})$ anhydrous pyridine was mixed with toluene to prepare $1 \mathrm{~mL}$ solution. $\mathrm{Co}(\mathrm{HMDS})_{2}(1.5 \mathrm{mg}, 3.9 \mu \mathrm{mol})$ was mixed with $62.5 \mu \mathrm{L}$ above pyridine in toluene solution, and was further diluted to $1 \mathrm{~mL}$ by adding $937.5 \mu \mathrm{L}$ toluene at room temperature. The mixture was stirred for 2 hours to ensure all $\mathrm{Co}(\mathrm{HMDS})_{2}$ dissolved. The Co-2 complex solution could be stored in the glove box freezer $\left(-30^{\circ} \mathrm{C}\right)$ no longer than seven days. 


\section{S2. Instrument and Characterization}

\section{S2.1 NMR}

All room temperature NMR and homodecoupling ${ }^{1} \mathrm{H}$ NMR spectra were recorded on Agilent U4-DD2 (400 MHz) or Bruker Avance II (500 MHz). Low temperature ${ }^{1} \mathrm{H}$ and ${ }^{13} \mathrm{C}$ NMR spectra were measured on Bruker Avance III (600 MHz) after the inner temperature of the NMR machine reached $-20{ }^{\circ} \mathrm{C}$ for $20 \mathrm{~min}$. The samples were kept at $-20{ }^{\circ} \mathrm{C} \pm 5{ }^{\circ} \mathrm{C}$ with a dry ice/ethylene glycol bath before the low-temperature NMR acquisition.

\section{S2.2 FTIR}

Fourier-transform infrared spectra were recorded on an Agilent Cary 630 FTIR spectrometer (Agilent Technologies Inc., Santa Clara, CA, USA) equipped with Diamond ATR and transmission sampling accessory.

\section{Monomer conversion measurement:}

A small aliquot of polymer solution $(20 \mu \mathrm{L})$ was removed out of the glove box and quenched with 5\% acetic acid / THF solution $(20 \mu \mathrm{L})$. The mixture $(\sim 10 \mu \mathrm{L})$ was immediately dropped onto the FTIR-ATR diamond sampler and formed a film within 10-20 seconds for the spectra measurement. The peak at $1800 \mathrm{~cm}^{-1}$ is assigned as the anhydride bond stretch in OCA; the peak at $1760 \mathrm{~cm}^{-1}$ corresponds to the formation of the ester bond in the polymer. The monomer conversion was determined by the intensity ratio between $1760 \mathrm{~cm}^{-1}$ and $1800 \mathrm{~cm}^{-1}$ : conversion $\%=\mathrm{I}_{1760} /\left(\mathrm{I}_{1760}+\mathrm{I}_{1800}\right){ }^{10}$

\section{S2.3 Gel permeation chromatography (GPC)}

GPC experiments were performed on a system equipped with an isocratic pump with degasser (Agilent 1260 series, Agilent Technologies, Santa Clara, CA, USA), Wyatt DAWN HELEOS multiangle laser light scattering (MALS) detector (GaAs $30 \mathrm{~mW}$ laser at $\lambda=690 \mathrm{~nm}$ ), and an Wyatt Optilab rEX differential refractive index (DRI) detector with a $690 \mathrm{~nm}$ light source (Wyatt Technology, Santa Barbara, CA, USA). Separations were performed using serially connected size exclusion columns (100 ̊, $500 \AA, 10^{3} \AA$, and $10^{4} \AA$ Phenogel columns, $5 \mu \mathrm{m}, 300 \times 4.6 \mathrm{~mm}$, Phenomenex, Torrance, CA, USA) at $35^{\circ} \mathrm{C}$ using THF as the mobile phase with a flow rate of $0.35 \mathrm{~mL} / \mathrm{min}$. The polymer molecular weight (MW) and molecular weight distribution $(\nexists)$ were determined using Zimm model fit of MALS-DRI data by ASTRA software (Version 6.1, Wyatt Technology). 
The refractive index increment $\mathrm{dn} / \mathrm{dc}$ value was determined by the Wyatt Optilab rEX refractive index detector using ASTRA software dn/dc template (Version 6.1, Wyatt Technology). Five polymer / THF solutions with different concentrations were sequentially injected into the refractive index detector and the refractive index values were plotted versus concentration in ASTRA software. The slope of the linear fitting data is the $\mathrm{dn} / \mathrm{dc}$ value.

The dn/dc values: poly(L-1), 0.1670; poly(L-2), 0.1377; poly(L-3), 0.1057; poly(L-4), 0.042; $\operatorname{poly}(\mathrm{L}-5), 0.084$.

\section{S2.4 DSC}

Differential scanning calorimetry (DSC) measurements were performed on TA Instruments DSC Q2000 instrument equipped with photocalorimeter accessory and RCS90 cooling system. Polymer samples in crimped aluminum pans were analyzed under nitrogen at a heating rate of $10{ }^{\circ} \mathrm{C} / \mathrm{min}$ from 0 to $220^{\circ} \mathrm{C}$. Glass transition temperature $\left(T_{\mathrm{g}}\right)$ and melting temperature $\left(T_{\mathrm{m}}\right)$ were obtained and reported from the second heating run.

\section{S2.5 Cyclic voltammetry}

Cyclic voltammetries (CVs) were performed in a three-electrode measurement setup in a glove box with a Gamry Interface 1010 potentiostat/galvanostat at a potential sweep rate of $50 \mathrm{mV} / \mathrm{s}$. The measurements were carried out in a $20 \mathrm{~mL}$ Gamry Dr. Bob's electrochemical cell with approximately $1 \mathrm{mM}$ concentration of Co complex in $0.1 \mathrm{M}$ tetra- $n$-butylammonium hexafluorophosphate (TBAH) in anhydrous THF, fitted with a glassy carbon working electrode ( $3 \mathrm{~mm}$ in diameter, Gamry), a $\mathrm{Ag} / \mathrm{AgNO}_{3}$ reference electrode (a silver wire in $0.01 \mathrm{M} \mathrm{AgNO}_{3}$ and $0.1 \mathrm{M}$ TBAH in anhydrous acetonitrile), and a platinum wire (Gamry) counter electrode. Ferrocene $(\mathrm{Fc})$ was measured as an internal standard, ${ }^{11}$ and all potentials versus $\mathrm{Fc} / \mathrm{Fc}^{+}$were subsequently referenced to SCE (adding $380 \mathrm{mV}$ ) based on the reported method. ${ }^{12}$ 


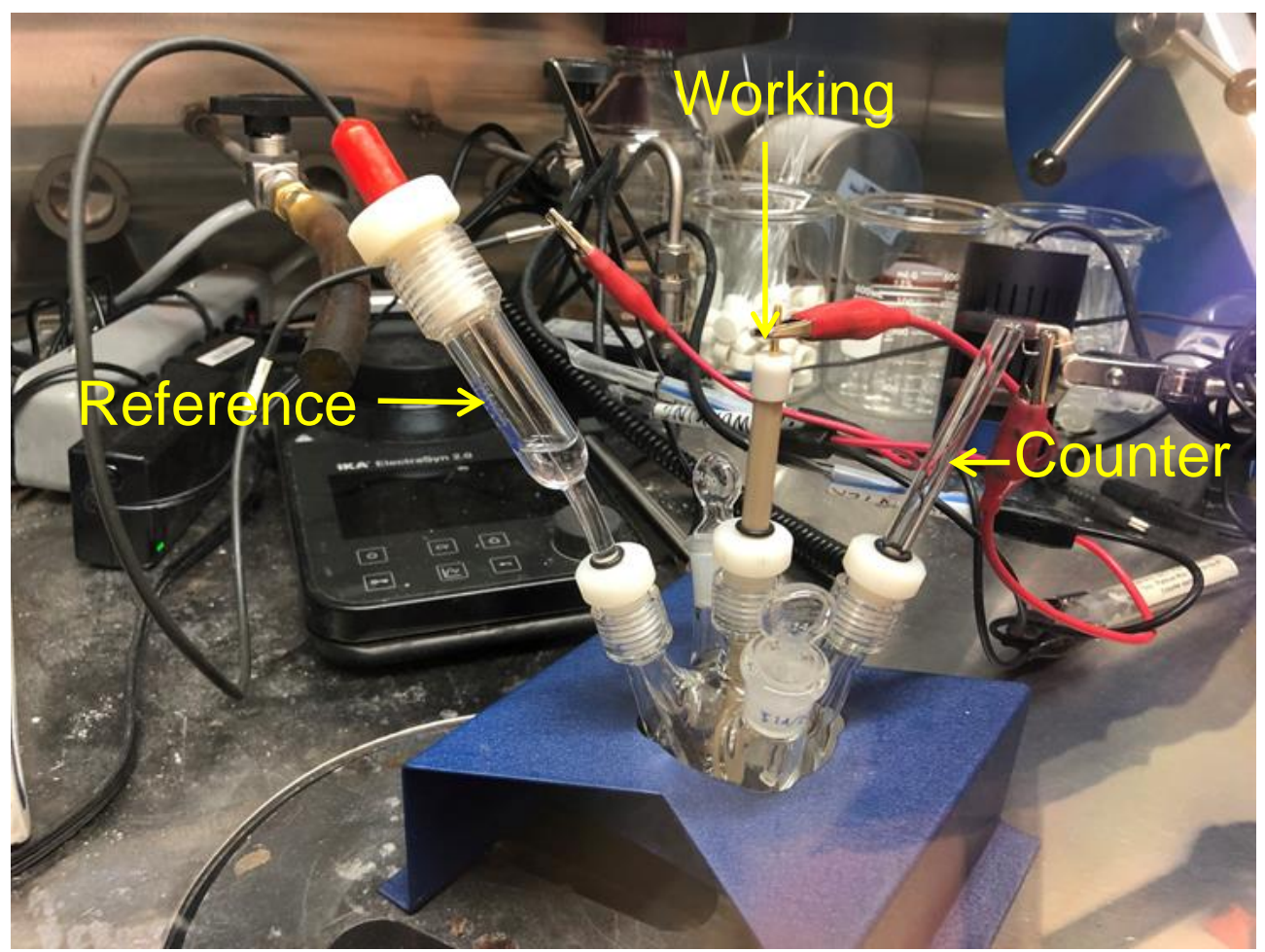

\section{S3. Polymerization Procedures}

\section{S3.1 The photoredox polymerization of L-1 initiated by Co-1 / Zn-1 / BnOH}

In a glove box, prior to the polymerization, all reagents were cooled in the cold trap equipped with a thermometer at $0{ }^{\circ} \mathrm{C}$, which was cooled by the liquid nitrogen and ethanol in a dewar. The monomer 1 (15 mg, $150 \mu \mathrm{L}$ of $100 \mathrm{mg} / \mathrm{mL}$ in THF, $0.078 \mathrm{mmol}, 700$ equiv.) was mixed with Co-1 $(9.9 \mu \mathrm{L}$ of $3.7 \mathrm{mg} / \mathrm{mL}$ in toluene, $0.112 \mu \mathrm{mol}, 1$ equiv.), $\mathbf{Z n - 1}$ (9.0 $\mu \mathrm{L}$ of $4.2 \mathrm{mg} / \mathrm{mL}$ in THF, $0.112 \mu \mathrm{mol}, 1$ equiv.), and $\mathrm{BnOH}(2.8 \mu \mathrm{L}$ of $3.7 \mathrm{mg} / \mathrm{mL}$ in THF, $0.112 \mu \mathrm{mol}, 1$ equiv.) in a 7-mL glass vial equipped with a magnetic stir bar. The solution was stirred and irradiated with a $34 \mathrm{~W}$ blue LED lamp (Kessil KSH150B LED Grow Light 150) at $-15 \pm 5^{\circ} \mathrm{C}$ (with a cooling fan to keep the reaction temperature) over 1-2 hours. The OCA monomer conversion was monitored by FTIR. The resulted polymer's MW and $\oslash$ were directly measured by GPC after the polymerization.

\section{S3.2 The electrochemical polymerization of L-1 initiated by Co-1 / Zn-1 / BnOH in IKA}

\section{ElectraSyn 2.0.}

In a glove box, prior to the polymerization, all reagents were cooled in the cold trap equipped with a thermometer at -5 to $0{ }^{\circ} \mathrm{C}$, which was cooled by ice water and $\mathrm{NaCl}$ in a dewar. Tetra- $n$ - 
butylammonium hexafluorophosphate (TBAH, $75.7 \mathrm{mg}$ ) was dissolved in THF (2 mL) to make 0.1 M TBAH/THF solution. The monomer L-1 (50 mg, $0.260 \mathrm{mmol}, 700$ equiv) was dissolved in $800 \mu \mathrm{L}$ TBAH/THF solution and was subsequently mixed with Co-1 (38.4 $\mu \mathrm{L}$ of $3.9 \mathrm{mg} / \mathrm{mL}$ in toluene, $0.372 \mu \mathrm{mol}, 1$ equiv.), $\mathbf{Z n - 1}$ (45.1 $\mu \mathrm{L}$ of $3.4 \mathrm{mg} / \mathrm{mL}$ in THF, $0.372 \mu \mathrm{mol}, 1$ equiv.) and $\mathrm{BnOH}(16.4 \mu \mathrm{L}$ of $2.6 \mathrm{mg} / \mathrm{mL}$ in THF, $0.372 \mu \mathrm{mol}, 1$ equiv.) in an ElectraSyn electrochemical cell (IKA, $5 \mathrm{~mL}$ ) equipped with a magnetic stir bar at $-5-0{ }^{\circ} \mathrm{C}$. The solution was diluted by $0.1 \mathrm{M}$ TBAH/THF solution to a final volume of $2 \mathrm{~mL}$. The ElectraSyn cell cap was loaded with a Mg anode and a Pt cathode plates (both from IKA, left panel), assembled with the cell, and plugged into ElectraSyn 2.0 via an IKA ElectraSyn GOGO extension module (right panel). The detailed ElectraSyn electrochemical cell assembly and program setup was also reported in the literature. ${ }^{13}$ The reaction was performed at $0{ }^{\circ} \mathrm{C}$ under a constant current of $4 \mathrm{~mA}$ over 1-2 hour. The OCA monomer conversion was monitored by FTIR. The obtained polymer solution was completely dried under vacuum and dialyzed to remove TBAH salt. MW and $\oslash$ were measured by GPC after the purification. Note for NMR studies, the polymer was only washed by methanol once to avoid excessive salt peaks in spectra while maintaining the structure information. Isolated yield: $79.9 \%$ after dialysis.

We note that the polymer can also be purified by methanol washing. After the electrochemical reaction, the resulted THF solution was dried and washed by cold methanol $(5-10 \mathrm{~mL})$ for three times to completely remove the salt solution. This method may result in the loss of polymers with lower yield compared with dialysis.

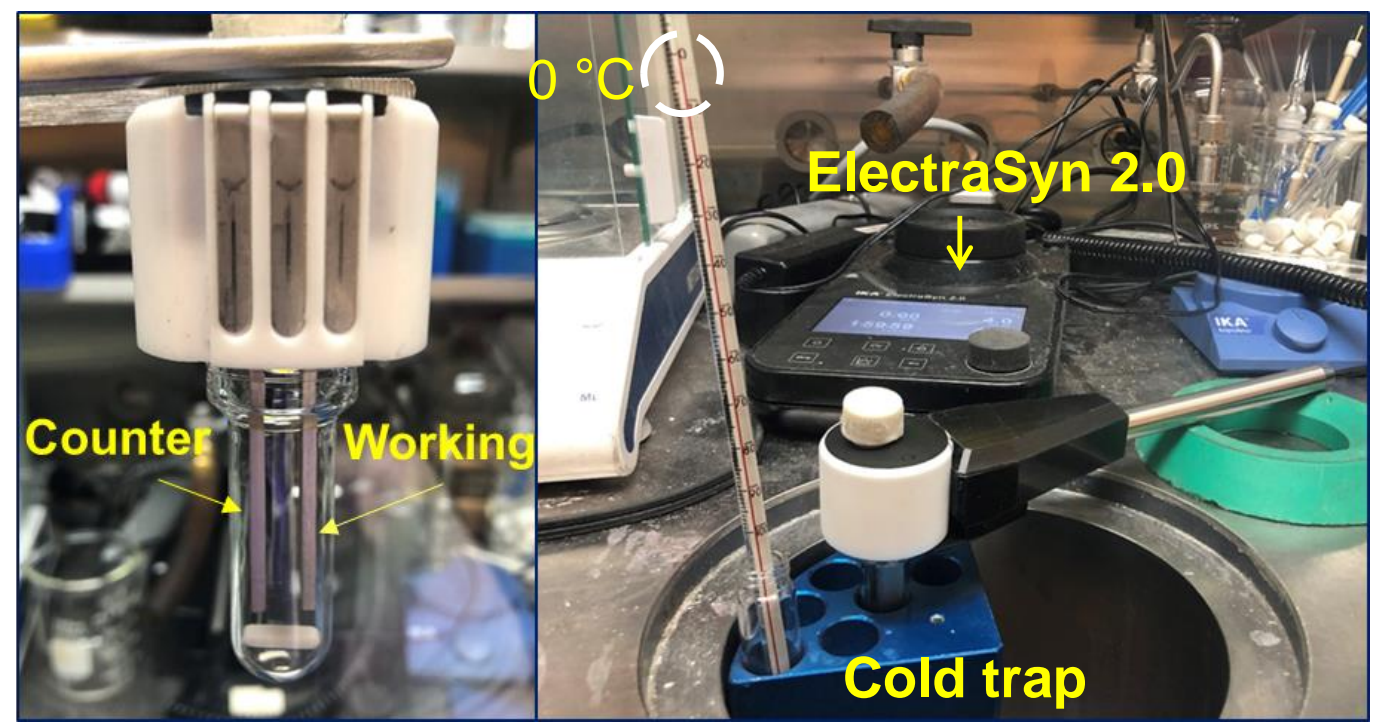




\section{S3.3 The electrochemical block copolymerization of L-1 and L-3 initiated by Co-1 / Zn-1 / $\mathrm{BnOH}$}

In a glove box, prior to the polymerization, all reagents were cooled in the cold trap equipped with a thermometer at -5 to $0{ }^{\circ} \mathrm{C}$, which was cooled by ice water and $\mathrm{NaCl}$ in a dewar. Similar to the procedures in $\mathbf{S 3 . 2}$ using $\mathrm{Mg}(+) / \mathrm{Pt}(-)$ electrodes, L-1 (50 mg, $800 \mu \mathrm{L}$ TBAH/THF solution, $0.260 \mathrm{mmol}, 200$ equiv) was mixed with Co-1 $(115 \mu \mathrm{L}$ of $4.3 \mathrm{mg} / \mathrm{mL}$ in toluene, $1.30 \mu \mathrm{mol}, 1$ equiv.), $\mathbf{Z n - 1}$ (316.7 $\mu \mathrm{L}$ of $1.6 \mathrm{mg} / \mathrm{mL}$ in THF, $1.30 \mu \mathrm{mol}, 1$ equiv.) and $\mathrm{BnOH}$ ( $46.9 \mu \mathrm{L}$ of 3.0 $\mathrm{mg} / \mathrm{mL}$ in THF, $1.30 \mu \mathrm{mol}, 1$ equiv.) in an ElectraSyn electrochemical cell equipped with a magnetic stir bar at $-5-0{ }^{\circ} \mathrm{C}$. The solution was diluted by $0.1 \mathrm{M}$ TBAH/THF solution to a final volume of $2 \mathrm{~mL}$. The solution was stirred at $0{ }^{\circ} \mathrm{C}$ under a constant current of $4 \mathrm{~mA}$ until complete consumption of L-1 within 30 min, monitored by FTIR. An aliquot of poly(L-1) solution $(500 \mu \mathrm{L})$ was taken out of the glove box for GPC characterization. The monomer L-3 ( $25.8 \mathrm{mg}, 500 \mu \mathrm{L} \mathrm{TBAH} / \mathrm{THF}$ solution, $97.7 \mu \mathrm{mol}, 100$ equiv.) was added into the remaining mixture and stirred at $0{ }^{\circ} \mathrm{C}$ with constant $4 \mathrm{~mA}$ current for 3 hours until complete consumption of the OCA monomers as monitored by FTIR. The resulted polymer solution was dialyzed against THF over 2 days. Both MW and $\oslash$ were directly measured by GPC after the dialysis.

\section{S3.4 The electrochemical polymerization of racemic L-1 and D-1 initiated by Co-1 / Zn-2}

In a glove box, prior to the polymerization, all reagents were cooled in the cold trap equipped with a thermometer at -5 to $0{ }^{\circ} \mathrm{C}$, which was cooled by ice water and $\mathrm{NaCl}$ in a dewar. Similar to the procedures in $\mathbf{S 3 . 4}$ using $\mathrm{Mg}(+) / \mathrm{Pt}(-)$ electrodes, $\mathrm{L}-\mathbf{1}(25 \mathrm{mg}, 250 \mu \mathrm{L}$ of $100 \mathrm{mg} / \mathrm{mL}$ in TBAH/THF solution, $0.130 \mathrm{mmol}, 200$ equiv.) and D-1 $(25 \mathrm{mg}, 250 \mu \mathrm{L}$ of $100 \mathrm{mg} / \mathrm{mL}$ in TBAH/THF solution, $0.130 \mathrm{mmol}, 200$ equiv.) were mixed with Co-1 $(88.7 \mu \mathrm{L}$ of $2.9 \mathrm{mg} / \mathrm{mL}$ in toluene, $0.651 \mu \mathrm{mol}, 1$ equiv.), $\mathbf{Z n - 2}(207 \mu \mathrm{L}$ of $7.4 \mathrm{mg} / \mathrm{mL}$ in THF, $0.651 \mu \mathrm{mol}, 1$ equiv) and $\mathrm{BnOH}(134.8 \mu \mathrm{L}$ of $2.25 \mathrm{mg} / \mathrm{mL}$ in THF, $0.651 \mu \mathrm{mol}, 1$ equiv.) in an ElectraSyn electrochemical cell equipped with a magnetic stir bar at $-5-0{ }^{\circ} \mathrm{C}$. The solution was diluted by $0.1 \mathrm{M}$ TBAH/THF solution to a final volume of $2 \mathrm{~mL}$. The solution was stirred at $0{ }^{\circ} \mathrm{C}$ under a constant current of 4 $\mathrm{mA}$ until complete consumption of OCA monomers as monitored by FTIR over 2 hours. The obtained polymer solution was completely dried under vacuum and washed by cold methanol to remove TBAH salt. Both MW and $\triangleq$ were directly measured by GPC after the purification. The $P_{\mathrm{m}}$ of poly $(\mathrm{rac}-\mathbf{1})$ was determined by ${ }^{13} \mathrm{C}$ NMR spectra.

\section{S3.5 Other ring-opening polymerization techniques}


The ring-opening polymerizations of OCAs initiated by (bpy) $\mathrm{Ni}(\mathrm{COD}) / \mathrm{Zn}(\mathrm{HMDS})_{2} / \mathrm{BnOH} /$ Ir-1 was reported in our previous work. ${ }^{10,14}$

\section{S3.6 Kinetic study of the electrochemical polymerization of OCA}

In a glove box, prior to the polymerization, all reagents were cooled in the cold trap equipped with a thermometer at -5 to $0{ }^{\circ} \mathrm{C}$, which was cooled by ice water and $\mathrm{NaCl}$ in a dewar. Similar to the procedures in $\mathbf{S 3 . 4}$ using $\mathrm{Mg}(+) / \mathrm{Pt}(-)$ electrodes, L-1 $(50 \mathrm{mg}$, in $800 \mu \mathrm{L} 0.1 \mathrm{M}$ TBAH/THF solution, $0.260 \mathrm{mmol}, 600$ equiv.) was mixed with Co-1 (38.3 $\mu \mathrm{L}$ of $4.3 \mathrm{mg} / \mathrm{mL}$ in toluene, 0.434 $\mu$ mol, 1 equiv.), Zn-1 (52.8 $\mu \mathrm{L}$ of $3.2 \mathrm{mg} / \mathrm{mL}$ in THF, $0.434 \mu \mathrm{mol}, 1$ equiv.) and BnOH (15.6 $\mu \mathrm{L}$ of $3.0 \mathrm{mg} / \mathrm{mL}$ in THF, $0.434 \mu \mathrm{mol}, 1$ equiv.) in an electrochemical cell $(5 \mathrm{~mL})$ equipped with a magnetic stir bar at $-5-0{ }^{\circ} \mathrm{C}$. The solution was diluted by $0.1 \mathrm{M}$ TBAH/THF solution to a final volume of $2 \mathrm{~mL}$. The mixture was stirred at $0{ }^{\circ} \mathrm{C}$ with constant $4 \mathrm{~mA}$ current. At the predetermined time point, $10 \mu \mathrm{L}$ of the polymer solution was taken out and immediately analyzed by FTIR.

All the catalysts' concentrations were varied, and the semi-logarithmic plots were drawn to calculate the kinetic constants and reaction orders according to the kinetic laws:

$-\mathrm{d}[\mathbf{1}] / \mathrm{d} t=k_{\mathrm{app}} \cdot[\mathbf{1}]$

where $k_{\mathrm{app}}$ is the apparent first-order rate constant. For eq. 1 it equals to

$\ln [\mathbf{1}]_{0} / \ln [\mathbf{1}]_{\mathrm{t}}=k_{\mathrm{app}} \cdot t+C$

thus $\ln [\mathbf{1}]_{0} / \ln [\mathbf{1}]_{\mathrm{t}}$ versus $t$ was plotted. 
Table S1. The discovery of Co-1/Zn-1 for the photoredox ring-opening polymerization of L$1^{a}$
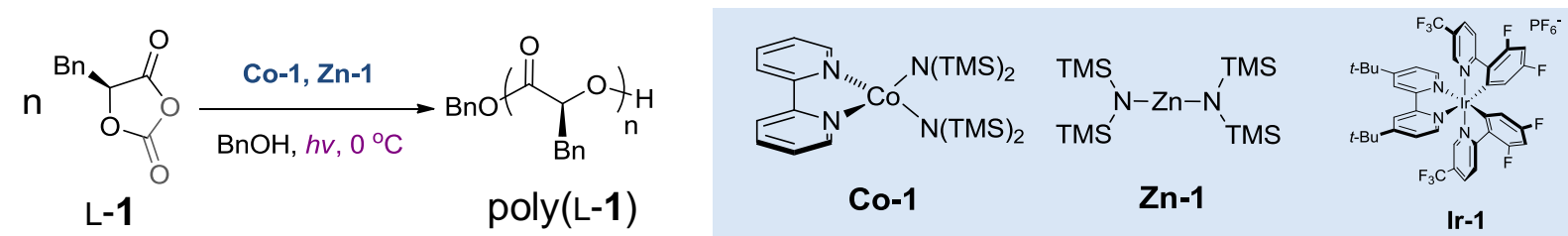

\begin{tabular}{|c|c|c|c|c|c|c|c|c|}
\hline Entry & Conditions & FR & $\begin{array}{c}\text { Time } \\
\text { (h) }\end{array}$ & $\begin{array}{l}\text { Conv. } \\
(\%)^{b}\end{array}$ & $M_{\mathrm{n}}(\mathrm{kDa})^{c}$ & $\mathrm{MW}_{\mathrm{cal}}(\mathrm{kDa})$ & $\mathrm{MW}_{\text {theo }}(\mathrm{kDa})$ & $\bigoplus^{c}$ \\
\hline 1 & As shown & 700 & 1 & 100 & 107.8 & 103.7 & 103.7 & 1.04 \\
\hline 2 & At $20{ }^{\circ} \mathrm{C}$ & 700 & 2 & 100 & 84.3 & 103.7 & 103.7 & 1.04 \\
\hline 3 & No Co-1 & 700 & 1 & 33 & 81.7 & 103.7 & 34.3 & 1.09 \\
\hline 4 & No Zn-1 & 700 & 1 & 19 & 16.9 & 103.7 & 19.7 & 1.41 \\
\hline 5 & Only Co-1 & 700 & 1 & 11 & 23.6 & 103.7 & 11.4 & 1.35 \\
\hline 6 & Only Zn-1 & 700 & 1 & 39 & 84.3 & 103.7 & 40.4 & 1.08 \\
\hline 7 & $\mathbf{C o - 1}+h v$ & 700 & 1 & 13 & 14.5 & 103.7 & 13.5 & 3.50 \\
\hline 8 & No BnOH & 700 & 1 & 67 & 108.7 & 103.7 & 69.5 & 1.05 \\
\hline 9 & No light & 700 & 1 & 69 & 96.9 & 103.7 & 71.6 & 1.06 \\
\hline 10 & $\begin{array}{l}\text { Adding } 0.1 \text { eq. } \\
\text { Ir-1 }\end{array}$ & 700 & 1 & 67 & 90.0 & 103.7 & 69.5 & 1.08 \\
\hline 11 & $\begin{array}{l}\mathbf{Z n - 2}+\mathrm{BnOH} \\
\quad(\text { no } \mathbf{C o - 1})\end{array}$ & 700 & 2 & 41 & 80.1 & 103.7 & 42.5 & 1.05 \\
\hline 12 & $\begin{array}{l}\mathbf{Z n - 3}+\mathrm{BnOH} \\
\quad(\text { no } \mathbf{C o - 1})\end{array}$ & 700 & 2 & 21 & 19.9 & 103.7 & 21.8 & 1.57 \\
\hline
\end{tabular}

\footnotetext{
${ }^{a}$ Abbreviations: FR, the feeding ratio of [L-1]/[Zn-1]; Conv., monomer conversion; $M_{\mathrm{n}}$, number-average molecular weight; $\mathrm{MW}_{\text {cal }}$, molecular weight calculated from the $\mathrm{FR}$, assuming $100 \%$ monomer conversion; $\mathrm{MW}_{\text {theo }}$, molecular weight calculated from the $\mathrm{FR}$ and the monomer conversion; $Ð$, molecular weight distribution. Polymerization conditions: $[\mathbf{C o - 1}]=[\mathbf{Z n - 1}]=[\mathrm{BnOH}]$ at $0{ }^{\circ} \mathrm{C}$ in a glove box.

${ }^{b}$ Determined from the intensity of the Fourier transform infrared peak at $1805 \mathrm{~cm}^{-1}$, which corresponds to the anhydride group of the $O$-carboxyanhydride.
} 
${ }^{c}$ Determined by gel-permeation chromatography.

\section{Discussion:}

Only Zn complex (Table S1 entry 6), or Zn alkoxide (entry 3) could initiate ROP with a conversion of $39 \%$ or $33 \%$, respectively. The ROP also proceeded to some extent without light (entry 9) or without electricity (Table 1, entry 7), with incomplete monomer conversions over the time (polymerization stopped, also see Table S6 entry 6). It is likely that Co/Zn complexes could initiate ROP in an uncontrolled manner without any external stimulus. Based on our previous reports, ${ }^{10} \mathrm{Zn}$ itself initiates ROP of OCAs via conventional coordination-insertion mechanism of ROP. Co complex may mediate oxidative insertion as $\mathrm{Ni}$ or $\mathrm{Co}$ complexes for NCA polymerization but in an inefficient way (Table S1, entry 5). ${ }^{15}$ However, Co-mediated decarboxylation is necessary for the chain propagation especially for high-MW polymer synthesis, as shown in Figure 1c. The inefficient decarboxylation, as previously investigated, ${ }^{10}$ is the problem for chain propagation in the ROP of OCAs to synthesize high-MW polyesters; and such problem can be overcome using our eROP method described here or our reported photoredox approach ${ }^{10 \mathrm{~b}}$ 
Table S2. Effects of solvent on the electrochemical ring-opening polymerization of L-1 mediated by $\mathrm{Co}-1 / \mathrm{Zn}-1 / \mathrm{BnOH}^{a}$

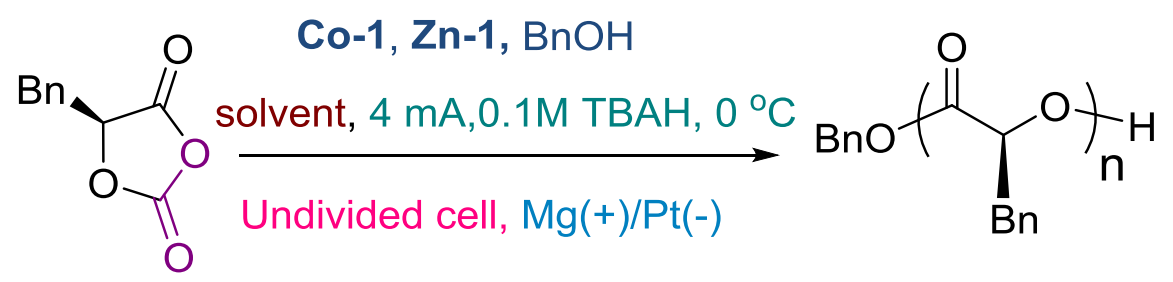

\begin{tabular}{ccccccccc}
\hline Entry & Solvent & FR & Temp. $\left({ }^{\circ} \mathrm{C}\right)$ & Time (h) & Conv. $(\%)^{b}$ & $M_{\mathrm{n}}(\mathrm{kDa})^{c}$ & $\mathrm{MW}_{\text {cal }}(\mathrm{kDa})$ & $\bigoplus^{c}$ \\
\hline 1 & THF & 700 & 0 & 1 & 100 & 103.5 & 103.7 & 1.06 \\
2 & DMF & 700 & 0 & 2 & 100 & 141.6 & 103.7 & 1.22 \\
3 & ACN & 700 & 0 & 2 & 100 & 26.9 & 103.7 & 1.17 \\
\hline
\end{tabular}

${ }^{a}$ Abbreviations: FR, the feeding ratio of $[\mathbf{1}] /[\mathbf{Z n}-\mathbf{1}]$; Conv., monomer conversion; Temp., temperature; $M_{\mathrm{n}}$, number-average molecular weight; $\mathrm{MW}_{\text {cal }}$, molecular weight calculated from the ratio of the amount of monomer to the amount of catalyst; $Ð$, molecular weight distribution. For all polymerization reactions, $[\mathbf{C o - 1}]=[\mathbf{Z n - 1}]=[\mathrm{BnOH}]$.

${ }^{b}$ Determined from the intensity of the Fourier transform infrared peak at $1805 \mathrm{~cm}^{-1}$, which corresponds to the anhydride group of the $O$-carboxyanhydride.

${ }^{c}$ Determined by gel-permeation chromatography. 
Table S3. Effects of electrolytes on the electrochemical ring-opening polymerization of L-1 mediated by $\mathrm{Co}-1 / \mathrm{Zn}-1 / \mathrm{BnOH}^{a}$

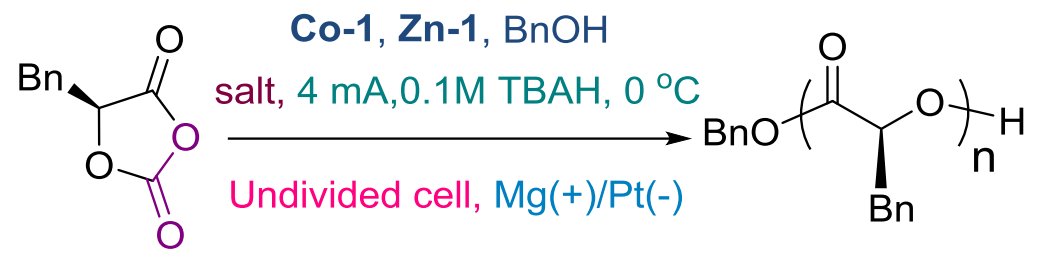

\begin{tabular}{cccccccccc}
\hline Entry & Salt $(0.1 \mathrm{M})$ & $\mathrm{FR}$ & $\begin{array}{c}\text { Temp. } \\
\left({ }^{\circ} \mathrm{C}\right)\end{array}$ & $\begin{array}{c}\text { Time } \\
(\mathrm{h})\end{array}$ & Conv. $(\%)^{b}$ & $M_{\mathrm{n}}(\mathrm{kDa})^{c}$ & $\begin{array}{c}\mathrm{MW}_{\text {cal }} \\
(\mathrm{kDa})\end{array}$ & $\begin{array}{c}\mathrm{MW}_{\text {theo }} \\
(\mathrm{kDa})\end{array}$ & $\Xi^{c}$ \\
\hline 1 & $n \mathrm{Bu}_{4} \mathrm{NPF}_{6}$ & 500 & 0 & 1 & 100 & 86.3 & 74.1 & 74.1 & 1.07 \\
2 & $n \mathrm{Bu}_{4} \mathrm{NPF}_{6}$ & 700 & 0 & 1 & 100 & 103.5 & 103.7 & 103.7 & 1.06 \\
3 & $n \mathrm{Bu}_{4} \mathrm{NBF}_{4}$ & 700 & 0 & 1 & 39 & 68.4 & 103.7 & 40.5 & 1.06 \\
4 & $n \mathrm{Bu}_{4} \mathrm{NBPh}_{4}$ & 700 & 0 & 1 & 0 & N.D. & 103.7 & 0 & N.D. \\
5 & $\mathrm{Et}_{4} \mathrm{NBF}_{4}$ & 700 & 0 & 1 & 0 & N.D. & 103.7 & 0 & N.D. \\
6 & $\mathrm{Et}_{4} \mathrm{NPF}_{6}$ & 700 & 0 & 1 & 48 & 52.3 & 103.7 & 49.8 & 1.81 \\
7 & $\mathrm{LiClO}_{4}$ & 700 & 0 & 1 & 22 & 23.2 & 103.7 & 22.9 & 1.09 \\
8 & $\mathrm{LiPF}_{6}$ & 700 & 0 & 1 & 80.5 & 71.7 & 103.7 & 83.5 & 1.13 \\
9 & $\mathrm{LiBF}_{4}$ & 700 & 0 & 1 & 0 & N.D. & 103.7 & 0 & N.D. \\
10 & $\mathrm{LiBr}^{2}$ & 700 & 0 & 1 & 0 & N.D. & 103.7 & 0 & N.D. \\
11 & $\mathrm{MgClO}_{4}$ & 700 & 0 & 1 & 0 & N.D. & 103.7 & 0 & N.D. \\
\hline
\end{tabular}

${ }^{a}$ Abbreviations: FR, the feeding ratio of $[\mathbf{1}] /[\mathbf{Z n}-1]$; Conv., monomer conversion; Temp., temperature; $M_{\mathrm{n}}$, number-average molecular weight; $\mathrm{MW}_{\text {cal }}$, molecular weight calculated from the FR, assuming $100 \%$ monomer conversion; $\mathrm{MW}_{\text {theo }}$, molecular weight calculated from the FR and the monomer conversion; $\doteq$, molecular weight distribution; N.D., not determined. For all polymerization reactions, $[\mathbf{C o - 1}]=[\mathbf{Z n - 1}]=$ $[\mathrm{BnOH}]$ in THF.

${ }^{b}$ Determined from the intensity of the Fourier transform infrared peak at $1805 \mathrm{~cm}^{-1}$, which corresponds to the anhydride group of the $O$-carboxyanhydride.

${ }^{c}$ Determined by gel-permeation chromatography. 
Table S4. Effects of current on the electrochemical ring-opening polymerization of L-1 mediated by $\mathrm{Co}-1 / \mathrm{Zn}-1 / \mathrm{BnOH}^{a}$

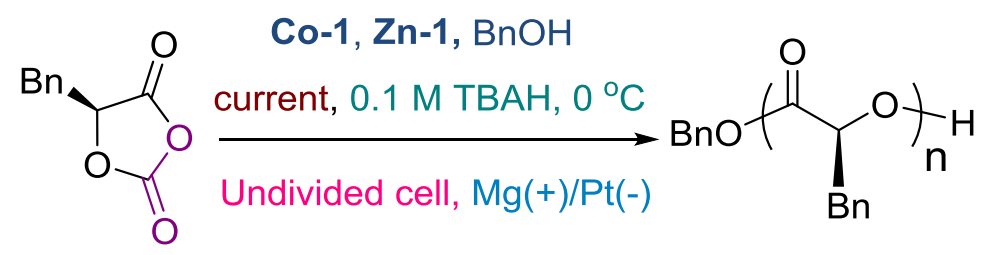

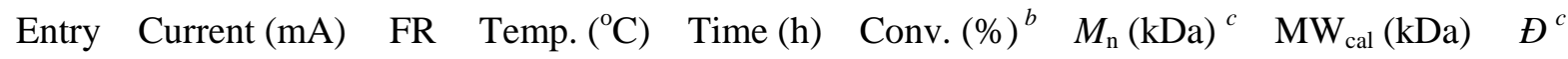

\begin{tabular}{lcccccccc}
\hline 1 & 2 & 700 & 0 & 2 & 82 & 94.0 & 103.7 & 1.04 \\
2 & 4 & 700 & 0 & 1 & 100 & 103.5 & 103.7 & 1.06 \\
3 & 6 & 700 & 0 & 0.75 & 100 & 94.8 & 103.7 & 1.03 \\
4 & 8 & 700 & 0 & 1 & 100 & 81.5 & 103.7 & 1.23 \\
\hline
\end{tabular}

${ }^{a}$ Abbreviations: FR, the feeding ratio of $[\mathbf{1}] /[\mathbf{Z n - 1}]$; Conv., monomer conversion; Temp., temperature; $M_{\mathrm{n}}$, number-average molecular weight; $\mathrm{MW}_{\text {cal }}$, molecular weight calculated from the ratio of the amount of monomer to the amount of catalyst; $Ð$, molecular weight distribution. For all polymerization reactions, $[\mathbf{C o - 1}]=[\mathbf{Z n - 1}]=[\mathrm{BnOH}]$ in THF.

${ }^{b}$ Determined from the intensity of the Fourier transform infrared peak at $1805 \mathrm{~cm}^{-1}$, which corresponds to the anhydride group of the $O$-carboxyanhydride.

${ }^{c}$ Determined by gel-permeation chromatography.

\section{Discussion:}

Though the increase of current could boost the polymerization rate, the resulted polymers had broad MW distributions and lower than expected MWs (entry 4). We also observed that more salt were deposited on the electrodes similar as those shown in Figure S8. This suggests the side reactions' rates could be also elevated upon the increase of current. Additionally, from the energy efficiency point of view, an optimal current should be low enough to ensure the controlled polymerization. Our experiments thus suggested that $4 \mathrm{~mA}$ is optimal than other settings. 
Table S5. Effects of Co-1 concentration on the electrochemical ring-opening polymerization of L-1 mediated by Co-1/Zn-1/BnOH ${ }^{a}$

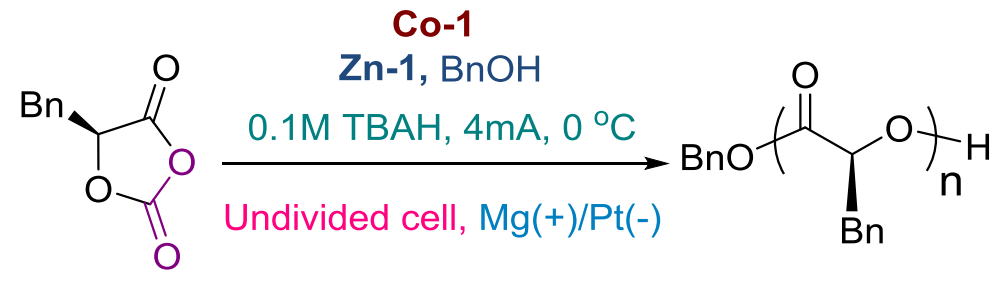

\begin{tabular}{ccccccccc}
\hline Entry & {$[\mathbf{C o}-1] /[\mathbf{Z n}-1]$} & FR & Temp. $\left({ }^{\circ} \mathrm{C}\right)$ & Time $(\mathrm{h})$ & Conv. $(\%)^{b}$ & $M_{\mathrm{n}}(\mathrm{kDa})^{c}$ & $\mathrm{MW}_{\text {cal }}(\mathrm{kDa})$ & $\Xi^{c}$ \\
\hline 1 & 0.5 & 700 & 0 & 2.5 & 100 & 99.7 & 103.7 & 1.03 \\
2 & 1 & 700 & 0 & 1 & 100 & 105.2 & 103.7 & 1.03 \\
3 & 2 & 700 & 0 & 1 & 100 & 96.8 & 103.7 & 1.03 \\
\hline
\end{tabular}

${ }^{a}$ Abbreviations: FR, the feeding ratio of $[\mathbf{1}] /[\mathbf{Z n - 1}]$; Conv., monomer conversion; Temp., temperature; $M_{\mathrm{n}}$, number-average molecular weight; $\mathrm{MW}_{\text {cal }}$, molecular weight calculated from the ratio of the amount of monomer to the amount of catalyst; $\nexists$, molecular weight distribution. For all polymerization reactions, $[\mathbf{Z n - 1}]=[\mathrm{BnOH}]$ in THF.

${ }^{b}$ Determined from the intensity of the Fourier transform infrared peak at $1805 \mathrm{~cm}^{-1}$, which corresponds to the anhydride group of the $O$-carboxyanhydride.

${ }^{c}$ Determined by gel-permeation chromatography. 
Table S6. Electrochemical ring-opening polymerization of L-1 mediated by Co-1/Zn$1 / \mathrm{BnOH}$ at various feeding ratios ${ }^{a}$

\begin{tabular}{cccccccccccc}
\multicolumn{2}{c}{$\mathrm{Co}-1, \mathrm{Zn}-1$} \\
\end{tabular}

\footnotetext{
${ }^{a}$ Abbreviations: FR, the feeding ratio of $[\mathbf{1}] /[\mathbf{Z n - 1}]$; Conv., monomer conversion; Temp., temperature; $M_{\mathrm{n}}$, number-average molecular weight; $\mathrm{MW}_{\text {cal }}$, molecular weight calculated from the FR, assuming $100 \%$ monomer conversion; $\mathrm{MW}_{\text {theo }}$, molecular weight calculated from the FR and the monomer conversion; $\oslash$, molecular weight distribution; N.D. not determined. For all polymerization reactions, $[\mathbf{C o - 1}]=[\mathbf{Z n - 1}]=$ $[\mathrm{BnOH}]$ in THF.

${ }^{b}$ Determined from the intensity of the Fourier transform infrared peak at $1805 \mathrm{~cm}^{-1}$, which corresponds to the anhydride group of the $O$-carboxyanhydride.

${ }^{c}$ Determined by gel-permeation chromatography.

${ }^{d}$ No current applied to the reaction. The entry is compared to Table 1 entry 7 , which confirming that the polymerization stopped when no current is applied. The results indicated that the electricity is necessary
} 
for chain propagation, though Co-1/Zn-1 (or Zn-1 itself) may be reactive for ring-opening reaction to convert certain monomers and to form short polymer chains.

${ }^{\boldsymbol{e}}$ The reaction was performed at $300 \mathrm{mg}$ scale of $\mathrm{L}-\mathbf{1}$. The resulted polymer was shown in the image next to the reaction scheme. 
Table S7. Measurement of residue metal concentrations in purified polymers by inductively coupled plasma mass spectrometry (ICP-MS) ${ }^{a}$

\begin{tabular}{c|cccc}
\hline & {$[\mathrm{Co}](\mathrm{ppb})$} & {$[\mathrm{Zn}](\mathrm{ppb})$} & {$[\mathrm{Mg}](\mathrm{ppb})$} & {$[\mathrm{Pt}](\mathrm{ppb})$} \\
\hline $\mathrm{HNO}_{3}$ & 0 & 18.6 & 18.8 & 0 \\
Electrochemical ROP & 22.8 & 53.2 & 1786.6 & 0.3 \\
\hline
\end{tabular}

${ }^{a}$ Abbreviations: ROP, ring-opening polymerizations; ppb: parts per billion, that equals to $\mu \mathrm{g} / \mathrm{L}$. The electrochemical polymerization reaction was performed at an $[\mathrm{L}-\mathbf{1}] /[\mathbf{Z n}-\mathbf{1}] /[\mathbf{C o - 1}] /[\mathrm{BnOH}]$ ratio of $700 / 1 / 1 / 1$ at $0{ }^{\circ} \mathrm{C}$ using $\mathrm{Mg}(+) / \mathrm{Pt}(-)$ electrodes, and the obtained polymer was washed by methanol. For ICP-MS studies, the polymer was dissolved in $10 \% \mathrm{HNO}_{3}$ at $70-80{ }^{\circ} \mathrm{C}$ at a concentration of $1 \mathrm{mg} / \mathrm{mL}$ for three days in order to completely degrade the polymer. The obtained polymer solution was then analyzed by ICP-MS. 
Table S8. Electrochemical polymerization and block copolymerization of various $O$ carboxyanhydrides ${ }^{a}$

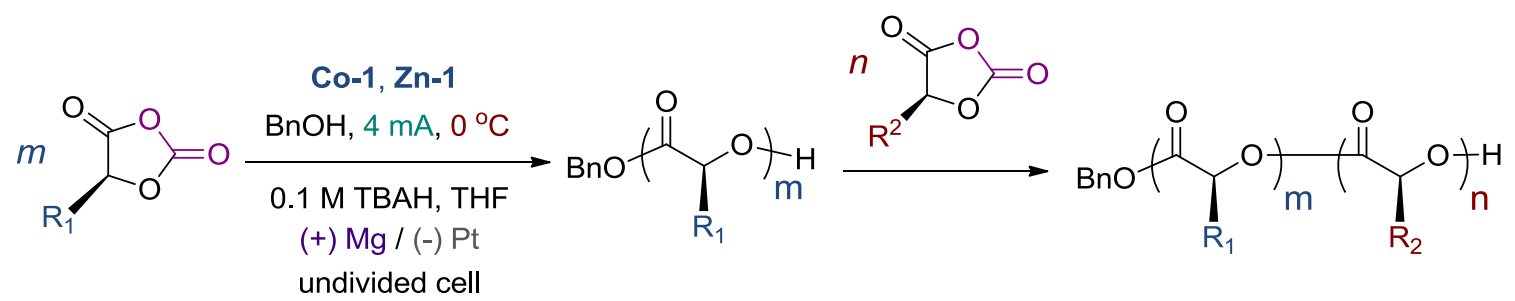

\begin{tabular}{|c|c|c|c|c|c|c|c|}
\hline Entry & Monomer & FR & Time (h) & $\underset{b}{\text { Conv. }}(\%)$ & $\begin{array}{c}M_{\mathrm{n}}\left(M_{\mathrm{n}}-\right. \\
\mathrm{b} 1)(\mathrm{kDa}){ }^{c}\end{array}$ & $\begin{array}{c}\mathrm{MW}_{\mathrm{cal}} \\
\left(\mathrm{MW}_{\mathrm{cal}}^{-}\right. \\
\mathrm{b} 1)(\mathrm{kDa})\end{array}$ & $\begin{array}{c}Ð \\
(\bigoplus-\mathrm{b} 1)^{c}\end{array}$ \\
\hline 1 & 2 & 200 & 1 & 100 & 37.0 & 35.7 & 1.06 \\
\hline 2 & 2 & 300 & 1.5 & 100 & 57.3 & 53.4 & 1.07 \\
\hline 3 & 2 & 400 & 2 & 100 & 71.8 & 71.3 & 1.03 \\
\hline 4 & 3 & 200 & 0.75 & 100 & 47.0 & 44.1 & 1.07 \\
\hline 5 & 3 & 300 & 1 & 100 & 64.3 & 66.1 & 1.04 \\
\hline 6 & 3 & 400 & 1.5 & 100 & 83.3 & 88.1 & 1.03 \\
\hline 7 & 4 & 300 & 1 & 100 & 55.8 & 21.7 & 1.06 \\
\hline 8 & 4 & 600 & 1 & 100 & 62.7 & 43.3 & 1.08 \\
\hline 9 & 5 & 50 & 1 & 100 & 15.3 & 6.8 & 1.14 \\
\hline 10 & 5 & 100 & 2 & 100 & 46.2 & 13.6 & 1.13 \\
\hline 11 & $1 / 3$ & $400 / 100$ & $1 / 2$ & 100 & $94.6(78.1)$ & $81.3(59.3)$ & $1.02(1.08)$ \\
\hline
\end{tabular}

${ }^{a}$ Abbreviations: FR, the feeding ratio of [OCA]/[Zn]; Conv., monomer conversion; Temp., temperature; $M_{\mathrm{n}}$, number-average molecular weight; $\mathrm{MW}_{\text {cal }}$, molecular weight calculated from the ratio of the amount of monomer to the amount of catalyst; $Ð$, molecular weight distribution. $M_{\mathrm{n}}$-b1 and $\emptyset$-b1 refer to the molecular weight and molecular weight distribution of the first block polymer.

${ }^{b}$ Determined from the intensity of the Fourier transform infrared peak at $1805 \mathrm{~cm}^{-1}$, which corresponds to the anhydride group of the OCA. 
${ }^{c}$ For homopolymers, $M_{\mathrm{n}}$ and $Ð$ were determined by gel-permeation chromatography. For copolymers, $M_{\mathrm{n}^{-}}$ b1, $Ð$, and $Ð$-b1 were determined by GPC; $M_{\mathrm{n}}$ of the block copolymer was calculated on the basis of the ${ }^{1} \mathrm{H}$ NMR integration ratio of the $\alpha$-methine peaks of the different blocks.

\section{Discussion:}

The higher-than-expected MWs of poly(L-4) and poly(L-5) may be due to incomplete initiation by $\mathrm{Zn}$-alkoxide or transesterification during the polymerization, which was also observed in the ROP of polylactide. ${ }^{8}$ 
Table S9. Electrochemical polymerization of racemic $O$-carboxyanhydrides ${ }^{a}$

\begin{tabular}{|c|c|c|c|c|c|c|c|c|c|c|}
\hline Entry & $\begin{array}{l}\text { OCA } \\
(\mathrm{FR})\end{array}$ & Co / Zn & $\begin{array}{l}\text { Time } \\
\text { (h) }\end{array}$ & $\begin{array}{l}\text { Conv. } \\
(\%)^{b}\end{array}$ & $\begin{array}{c}M_{\mathrm{n}} \\
(\mathrm{kDa})^{c}\end{array}$ & $\begin{array}{l}\mathrm{MW}_{\text {cal }} \\
(\mathrm{kDa})\end{array}$ & $\begin{array}{c}\mathrm{MW}_{\text {theo }} \\
(\mathrm{kDa})\end{array}$ & $\bigoplus^{c}$ & $P_{\mathrm{m}}^{d}$ & $T_{\mathrm{g}}{ }^{e}$ \\
\hline 1 & $\begin{array}{l}r a c-1 \\
(400)\end{array}$ & Co-1 / Zn-1 & 2 & 17 & N.D. & 59.3 & 10.2 & N.D. & N.D. & N.D. \\
\hline 2 & $\begin{array}{l}r a c-1 \\
(300)\end{array}$ & Co-1 / Zn-2 & 1 & 100 & 67.2 & 44.5 & 44.5 & 1.05 & 0.95 & 46 \\
\hline 3 & $\begin{array}{l}r a c-\mathbf{1} \\
(300)\end{array}$ & Co-1 / Zn-3 & 1 & 100 & 46.2 & 44.5 & 44.5 & 1.13 & 0.62 & N.D. \\
\hline 4 & $\begin{array}{l}r a c-1 \\
(200)\end{array}$ & Co-2 / Zn-1 & 1 & 24 & N.D. & 29.7 & 7.2 & N.D. & N.D. & N.D. \\
\hline 5 & $\begin{array}{l}r a c-1 \\
(300)\end{array}$ & Co-2 / Zn-3 & 1 & 100 & 46.2 & 44.5 & 44.5 & 1.07 & $0.21^{f}$ & 58 \\
\hline 6 & $\begin{array}{l}r a c-\mathbf{1} \\
(200)\end{array}$ & Co-2 / Zn-2 & 2 & 100 & 58.5 & 29.7 & 29.7 & 1.06 & 0.58 & N.D. \\
\hline 7 & $\begin{array}{l}r a c-3 \\
(200)\end{array}$ & Co-1 / Zn-2 & 1 & 100 & 34.7 & 44.1 & 44.1 & 1.04 & 0.98 & 4 \\
\hline 8 & $\begin{array}{l}r a c-4 \\
(300)\end{array}$ & Co-1 / Zn-2 & 1 & 100 & 32.2 & 21.7 & 21.7 & 1.08 & 0.90 & 50 \\
\hline 9 & $\begin{array}{l}r a c-4 \\
(300)\end{array}$ & Co-2 / Zn-3 & 1 & 100 & 49.6 & 21.7 & 21.7 & 1.07 & 0.89 & 50 \\
\hline 10 & $\begin{array}{l}r a c-1 \\
(300)\end{array}$ & $\begin{array}{c}\text { Co-1 / Zn-2 } \\
\text { no current }\end{array}$ & 2 & 21.1 & N.D. & 44.5 & 9.5 & N.D. & N.D. & N.D. \\
\hline 11 & $\begin{array}{l}r a c-\mathbf{1} \\
(300)\end{array}$ & $\begin{array}{c}\text { Co-1 / Zn-2 } \\
\text { no current }\end{array}$ & 4 & 25.5 & N.D. & 44.5 & 11.4 & N.D. & N.D. & N.D. \\
\hline 12 & $\begin{array}{l}r a c-\mathbf{1} \\
(300)\end{array}$ & $\begin{array}{c}\text { Co-2 / Zn-3 } \\
\text { no current }\end{array}$ & 2 & 14.8 & N.D. & 44.5 & 6.7 & N.D. & N.D. & N.D. \\
\hline 13 & $\begin{array}{l}r a c-\mathbf{1} \\
(300)\end{array}$ & $\begin{array}{c}\text { Co-2 / Zn-3 } \\
\text { no current }\end{array}$ & 4 & 16.9 & N.D. & 44.5 & 7.6 & N.D. & N.D. & N.D. \\
\hline 14 & $\begin{array}{l}r a c-\mathbf{1} \\
(300)\end{array}$ & $\begin{array}{c}\text { Zn-2 (no Co } \\
\text { complex) }\end{array}$ & 2 & $<5 \%$ & N.D. & 44.5 & 0 & N.D. & N.D. & N.D. \\
\hline 15 & $\begin{array}{l}r a c-1 \\
(300)\end{array}$ & $\begin{array}{c}\mathbf{Z n - 3} \text { (no Co } \\
\text { complex) }\end{array}$ & 2 & $<5 \%$ & N.D. & 44.5 & 0 & N.D. & N.D. & N.D. \\
\hline
\end{tabular}


${ }^{a}$ Abbreviations: FR, the feeding ratio of $[\mathbf{1}] /[\mathbf{Z n - 1}]$; Conv., monomer conversion; Temp., temperature; $M_{\mathrm{n}}$, number-average molecular weight; $\mathrm{MW}_{\text {cal }}$, molecular weight calculated from the FR, assuming $100 \%$ monomer conversion; $\mathrm{MW}_{\text {theo }}$, molecular weight calculated from the FR and the monomer conversion; $\oslash$, molecular weight distribution; $P_{\mathrm{m}}$, maximum probability of meso dyad formation. Polymerization conditions: $[\mathrm{L}-\mathrm{OCA}] /[\mathrm{D}-\mathrm{OCA}]=1 / 1,[\mathrm{Co}] /[\mathrm{Zn}] /[\mathrm{BnOH}]=1 / 1 / 1,00{ }^{\circ} \mathrm{C}, \quad 4 \mathrm{~mA}$ in $0.1 \mathrm{M}$ tetrabutylammonium hexafluorophosphate/THF solution, $\mathrm{Mg}(+) / \mathrm{Pt}(-)$ electrodes.

${ }^{b}$ Determined from the intensity of the Fourier transform infrared peak at $1805 \mathrm{~cm}^{-1}$, which corresponds to the anhydride group of the $O$-carboxyanhydride.

${ }^{c}$ Determined by gel-permeation chromatography.

${ }^{d}$ Determined by ${ }^{13} \mathrm{C}$ NMR spectroscopy. See NMR spectra in Figure S15 and S18.

${ }^{e}$ Determined by differential scanning calorimetry. See Figure S17 and its discussion of results.

${ }^{f} P_{\mathrm{r}}=1-P_{\mathrm{m}}=0.79$

\section{Discussion:}

For entries 10-15, we note that the prolonged reaction time would not improve the monomer conversions. The prolonged reaction time would not improve the monomer conversion (chain end likely dead). We also note that it is very difficult to separate and purify oligomers in those entries for detailed microstructure analysis, as dialysis and washing significantly could further decrease the yield of such oligomers. 


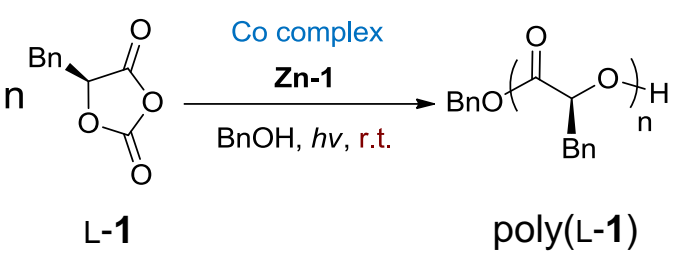

\section{Col complex}<smiles>[GeH3][Te]1=CC=CC1</smiles>

Conversion: $27 \%$

Coll complex
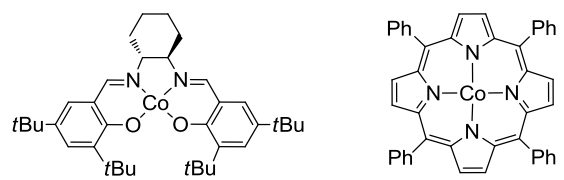

Conversion: $62 \%$

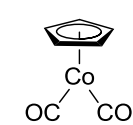

Conversion: $53 \%$
Co complex screen for photoredox ROP $-1^{\text {st }}$ round

$[1] /[\mathrm{Co}] /[\mathrm{Zn}-1] /[\mathrm{BnOH}]=600 / 1 / 1 / 1,2 h$, r.t. $h v$; $\mathrm{MW}_{\text {cal }}=88.9 \mathrm{kDa}$

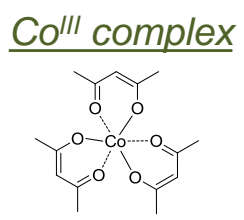

Conversion: $57 \%$

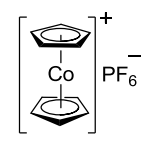

Conversion: $57 \%$

\section{Ligand for Co(HMDS) ${ }_{2}$}<smiles>C1CCOC1</smiles>

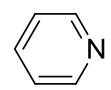

$M_{\mathrm{n}}: 66.0 \mathrm{kDa} ; \boxminus: 1.13$
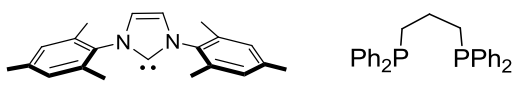

$M_{\mathrm{n}}: 48.1 \mathrm{kDa} ; \emptyset: 1.03$
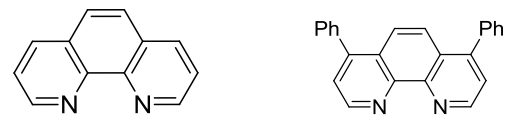

$M_{\mathrm{n}}: 86.2 \mathrm{kDa} ; \emptyset: 1.05$

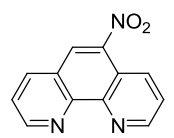

Conversion $76 \%$
$M_{\mathrm{n}}: 89.6 \mathrm{kDa} ; \oplus: 1.05$

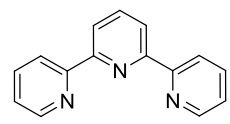

$M_{\mathrm{n}}: 73.3 \mathrm{kDa} ; \emptyset: 1.06$

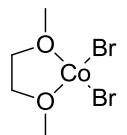

Conversion: $23 \%$

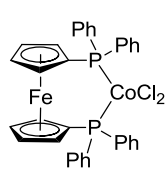

Conversion: $44 \%$ 
(a)
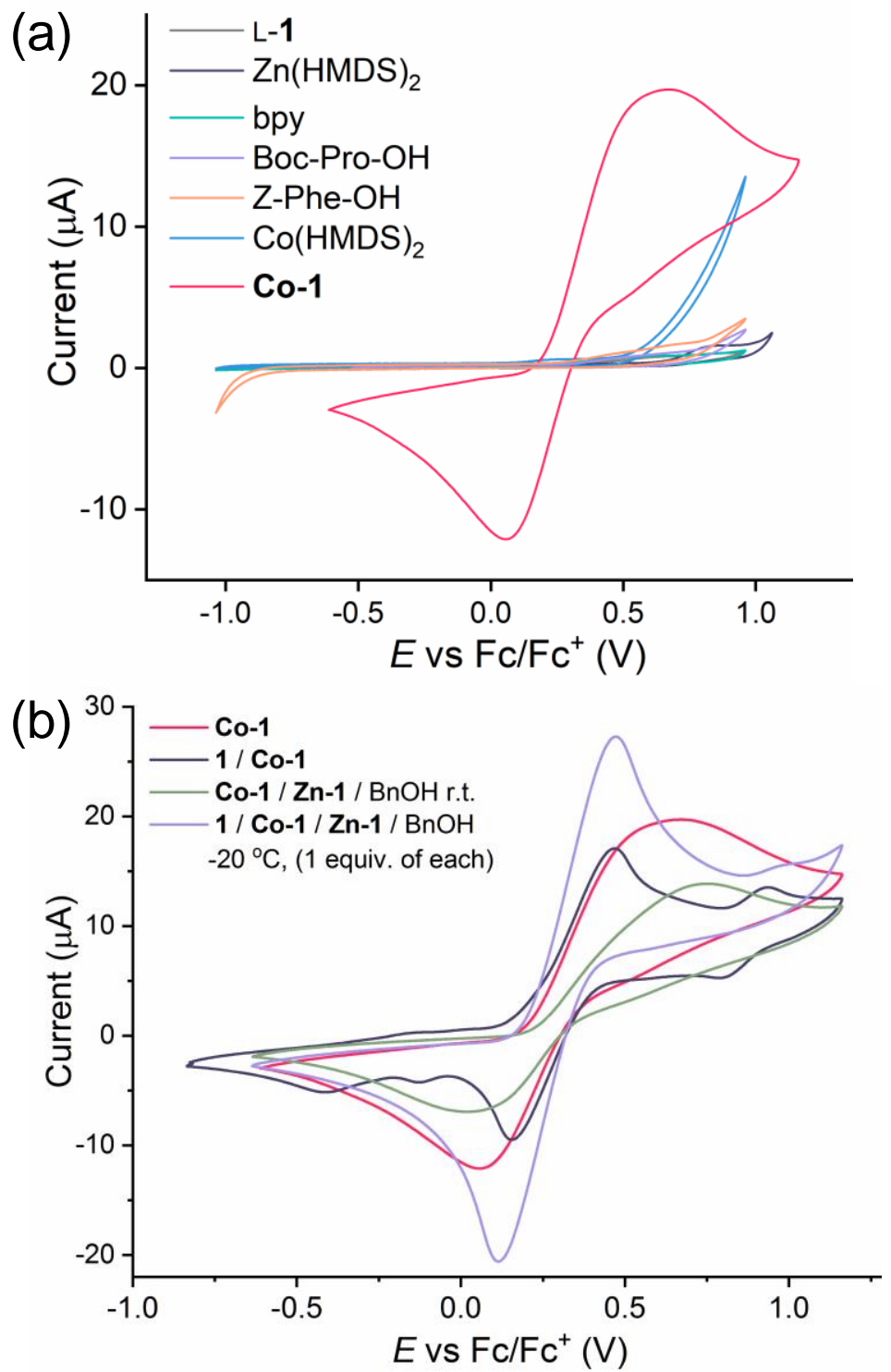

(c) $\left.{ }^{8}\right]$ eROP condition:

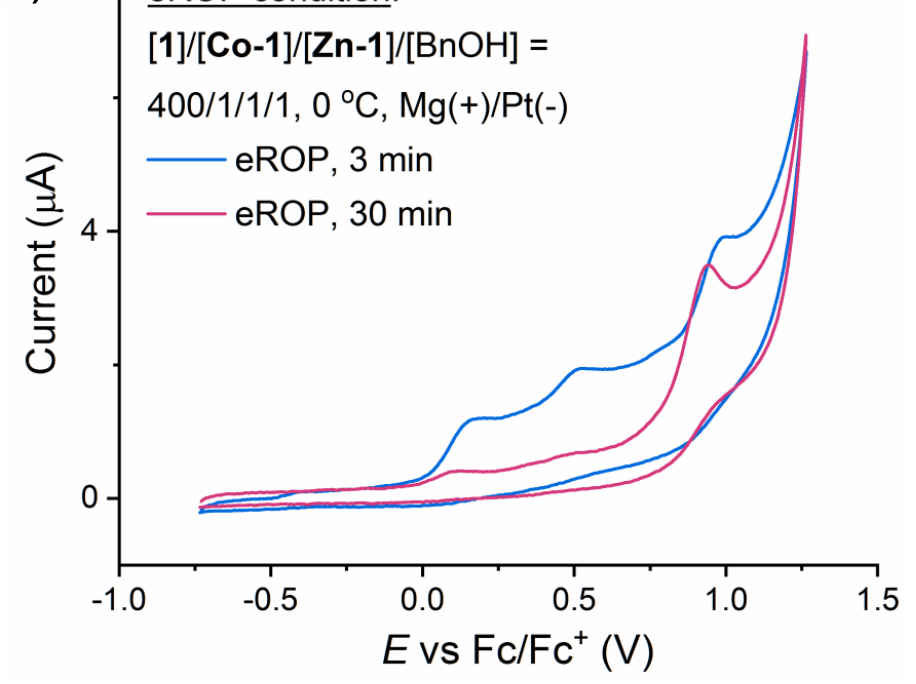


Figure S2. Cyclic voltammetry of (a) various reagents including OCA monomers, $\mathbf{Z n - 1}$ and amino acids comparing to Co-1, (b) Co-1 and the ring-opening reaction mixtures (1 equiv. of each) and (c) eROP of L-1 at $0{ }^{\circ} \mathrm{C}$ mediated by Co-1/Zn-1 $([\mathrm{L}-\mathbf{1}] /[\mathbf{C o}-\mathbf{1}] /[\mathbf{Z n}-\mathbf{1}] /[\mathrm{BnOH}]=$ 400/1/1/1). Scan rate: $50 \mathrm{mV} / \mathrm{s}$; solvent: $0.1 \mathrm{M} \mathrm{TBAH}$ in THF.

\section{Discussion:}

As our polymerization reactions were performed in THF, we did not choose acetonitrile, which is commonly used in the literature, as the solvent for CV studies. CV data in (a) suggested that $\mathbf{Z n -}$ 1, Co(HMDS $)_{2}$ and OCA monomer alone did not have strong redox properties. Our data in (b) agrees well with the literature that also showed the reduction potentials of $\mathrm{Co}^{\mathrm{III}} / \mathrm{Co}^{\mathrm{II}}$ (corresponding to the peak $\sim 0.5 \mathrm{~V}$ vs $\mathrm{Fc} / \mathrm{Fc}^{+}$); ${ }^{16}$ while the reduction potential of $\mathrm{Co}{ }^{\mathrm{II}} / \mathrm{Co}^{\mathrm{I}}$ often negative vs SCE. ${ }^{16 c}$, $16 \mathrm{~d}$ The peak around $1 \mathrm{~V}$ vs $\mathrm{Fc} / \mathrm{Fc}^{+}$could be assigned as $\mathrm{Co}^{\mathrm{III}}$ radical species, ${ }^{17}$ which was indicated by the use of DPPH scavenger as described in our main text, or other $\mathrm{Co}^{\text {III }}$ related species that requires additional mechanism studies and spectroscopies to find out. The results in (c) indicated that the redox reaction (more obviously, oxidation) of $\mathrm{Co}^{\mathrm{III}} / \mathrm{Co}^{\mathrm{II}}$ occurred in the early stage of the reaction, which may come from the major $\mathrm{Co}^{\mathrm{III}} / \mathrm{Co}^{\mathrm{II}}$ peaks $(\sim$ $0.5 \mathrm{~V}$ ) in the equivalent mixture of OCA monomer and metal complexes in (b); whereas peaks of $\mathrm{Co}^{\mathrm{III}}(\sim 1 \mathrm{~V})$ dominated in the late stage, suggesting that the initial oxidative insertion into OCA by $\mathrm{Co}^{\mathrm{II}}$ finished up and $\mathrm{Co}^{\mathrm{III}}$ mediated decarboxylation became influential for chain propagation. 


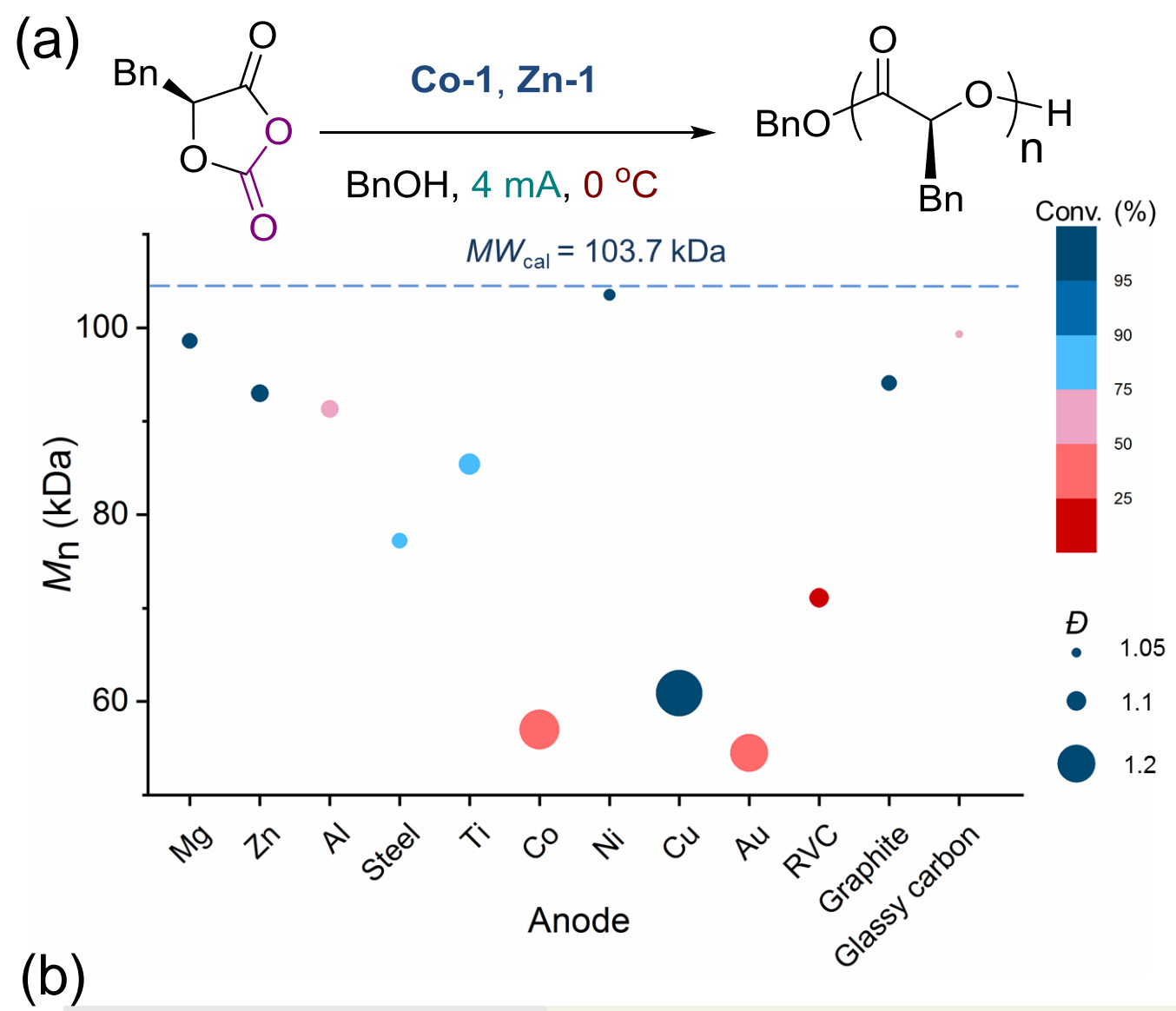

(b)

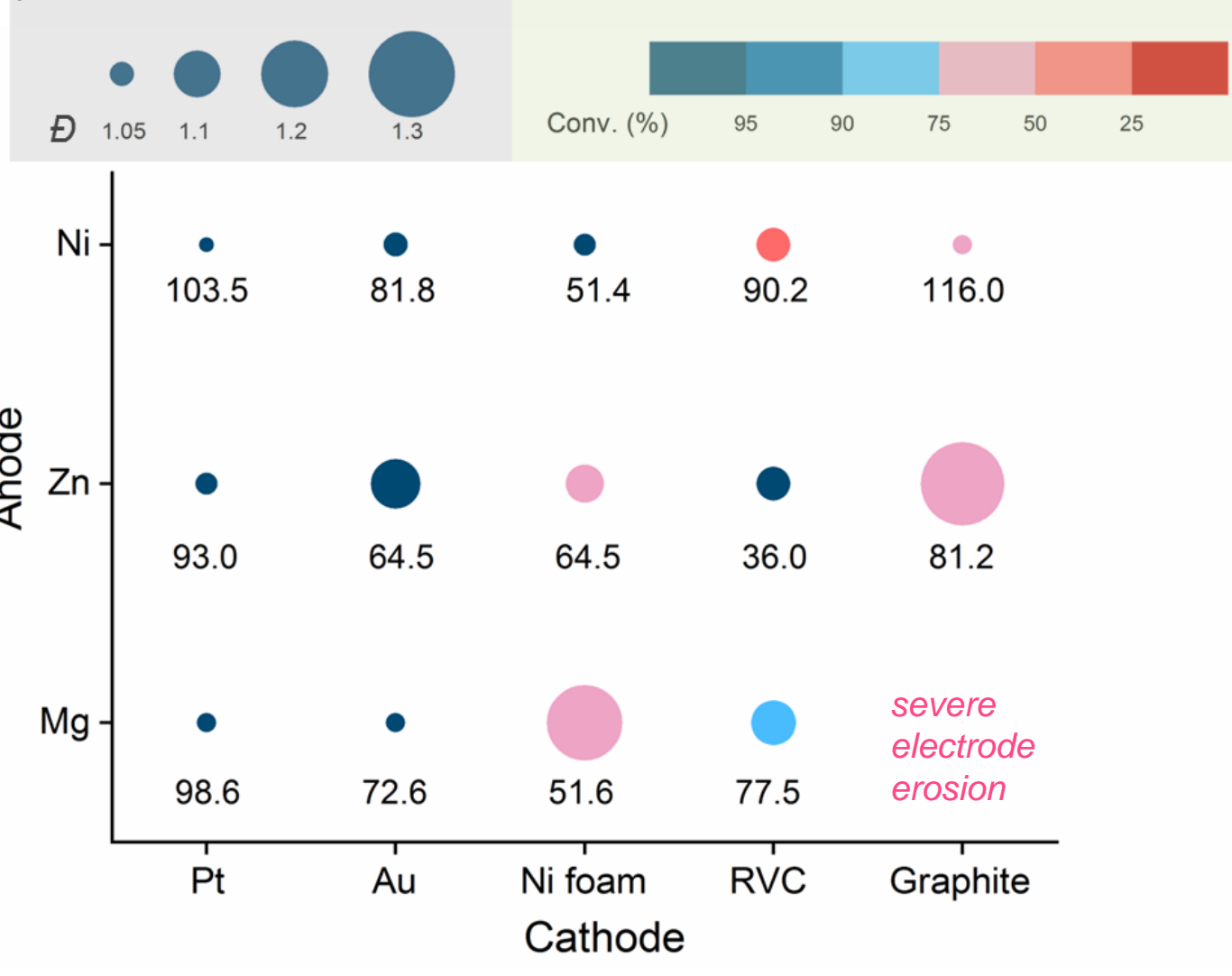


Figure S3. Screen of electrode materials for electrochemical polymerization of L-1. (a) Screen of anodes when using $\mathrm{Pt}$ as the cathode in the electrolysis at room temperature with $4 \mathrm{~mA}$ current for 2 hours ([L-1]/[Co-1]/[Zn-1] = 700/1/1). (b) Screen of the Cathode when selecting Ni, Zn and Mg as the anodes based on results in (a) $([\mathrm{L}-\mathbf{1}] /[\mathbf{C o}-1] /[\mathbf{Z n - 1}]=700 / 1 / 1)$. Note that the best results are represented in dark blue (high monomer conversion) and small circle (low $Ð$ ).

\section{Discussion:}

Based on the results in Figure S3, we found that $\mathrm{Mg}$ and $\mathrm{Ni}$ were optimal for the anode (working electrode) at a [L-1]/[Zn-1] ratio of 700/1. However, at a [L-1]/[Zn-1] ratio of $900 / 1$ at $0{ }^{\circ} \mathrm{C}$, reaction using $\mathrm{Mg}$ as the anode (100\% in 2 hours) was faster than that using $\mathrm{Ni}$ as the anode (90\% in three hours). Thus we decide to use $\mathrm{Mg}$ as the anode for the eROP of OCAs. 


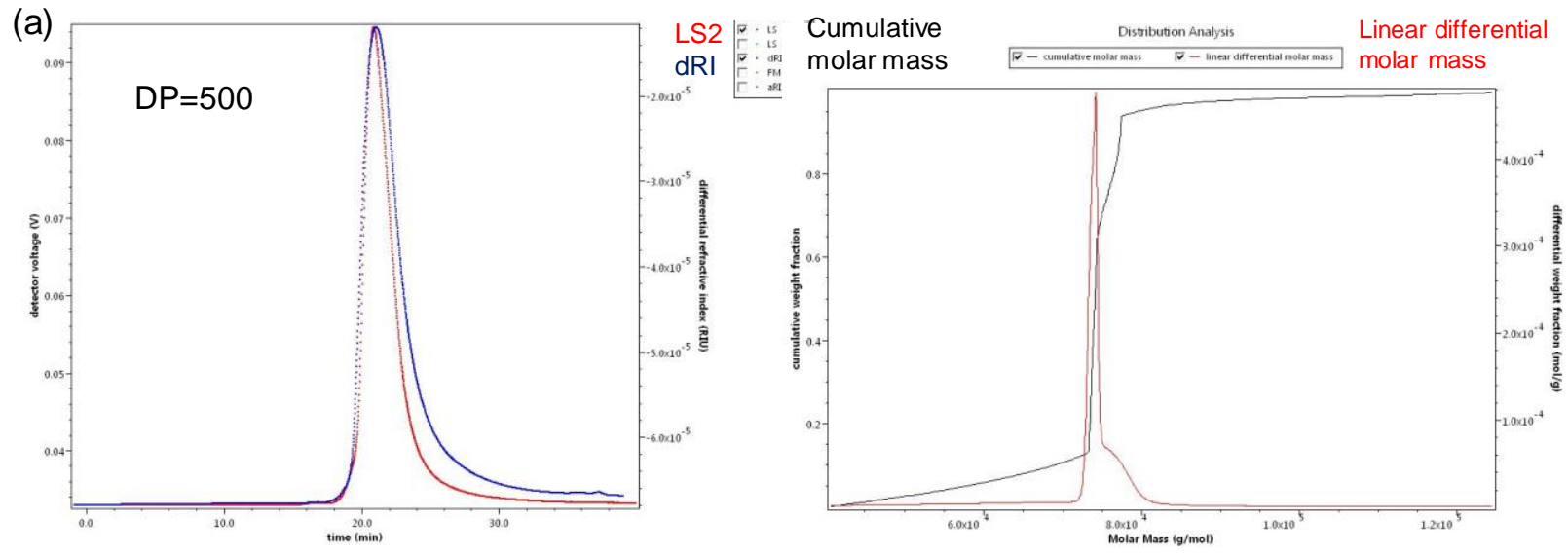

(b)

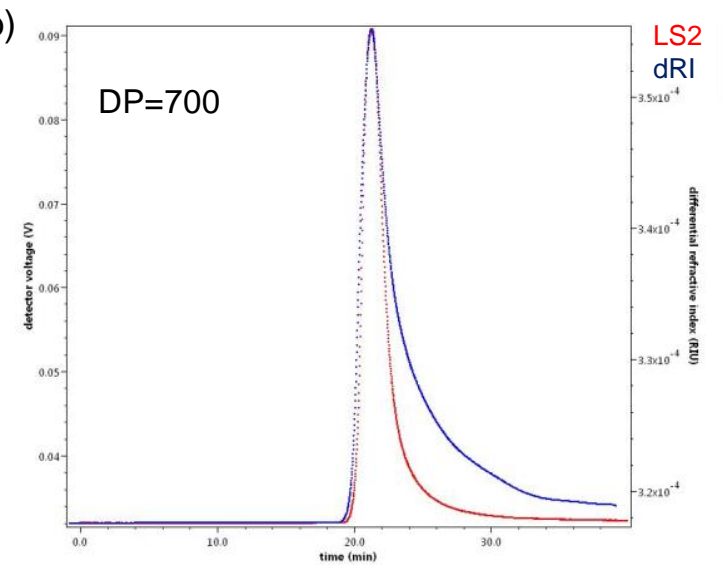

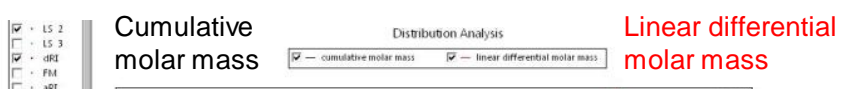

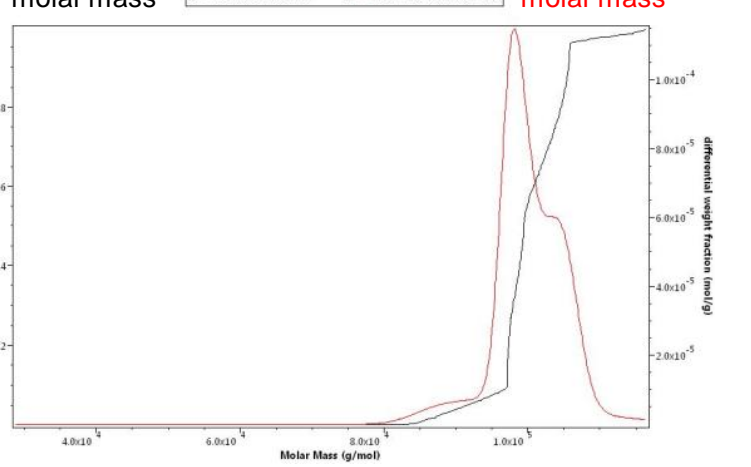

(c)

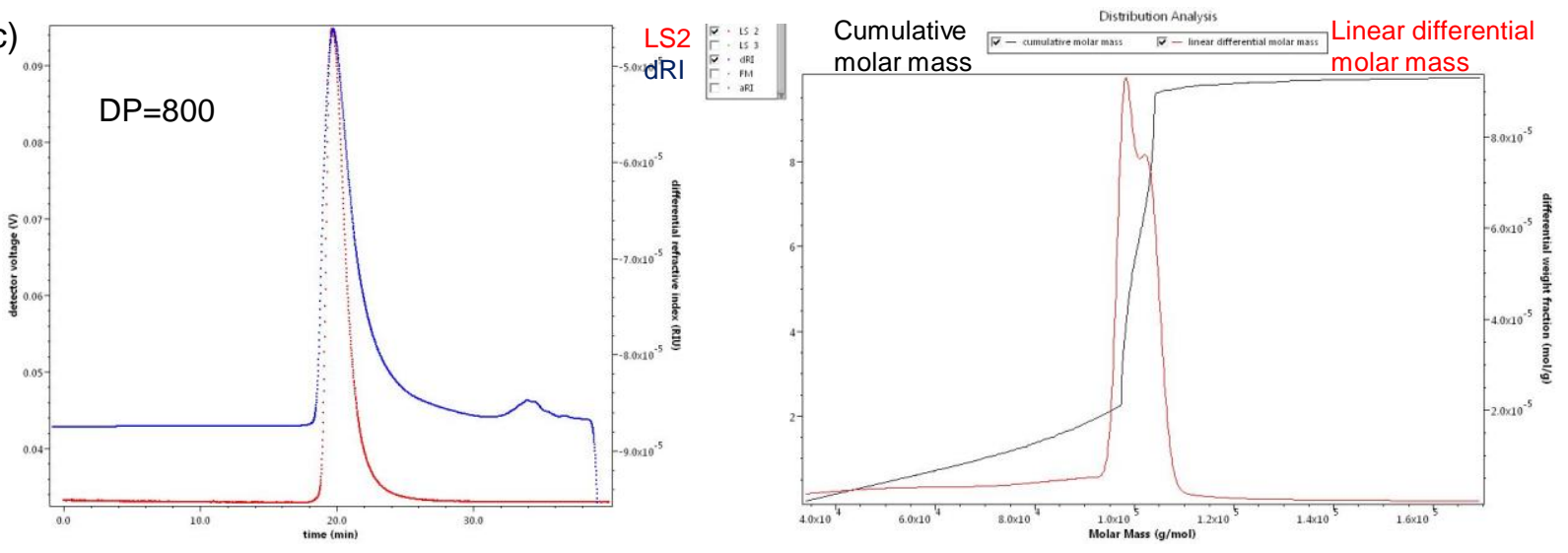



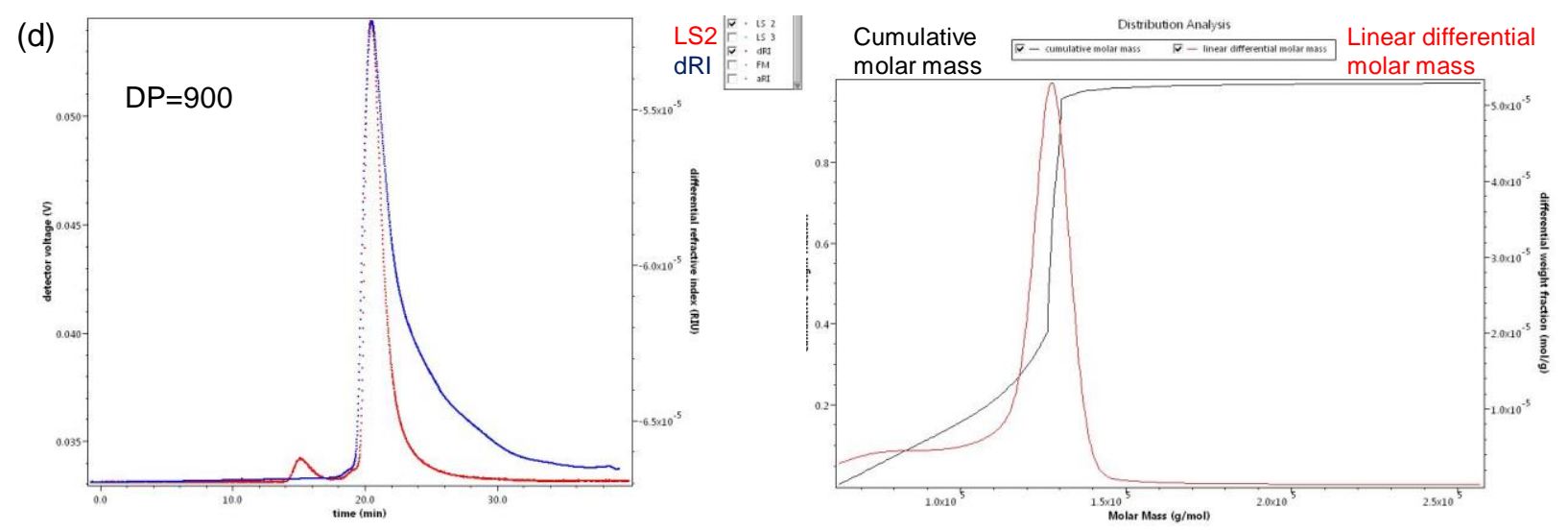

Figure S4. The GPC traces of poly(L-1) at different $[\mathrm{L}-\mathbf{1}] /[\mathbf{Z n - 1}]$ ratios (left column, both lightscattering and refractive index detector traces) and differential molecular weight distribution analysis (right column) of the GPC data in Figure 1a, obtained from Wyatt ASTRA software. For the differential molecular weight distribution analysis, the ASTRA software looks at the ratio of scattered light (from light scattering detector) to concentration in each and every data "slice" (from refractive index detector) and calculates a molecular weight. A "slice" of data is determined by a 0.5 second (default value) interval during the data acquisition. The differential weight molar mass distribution (right column red line) reflects the exact molar mass distribution information, based on the data from both detectors. All data showed the monodispersed and narrow molecular weight distributions for all polymers. 


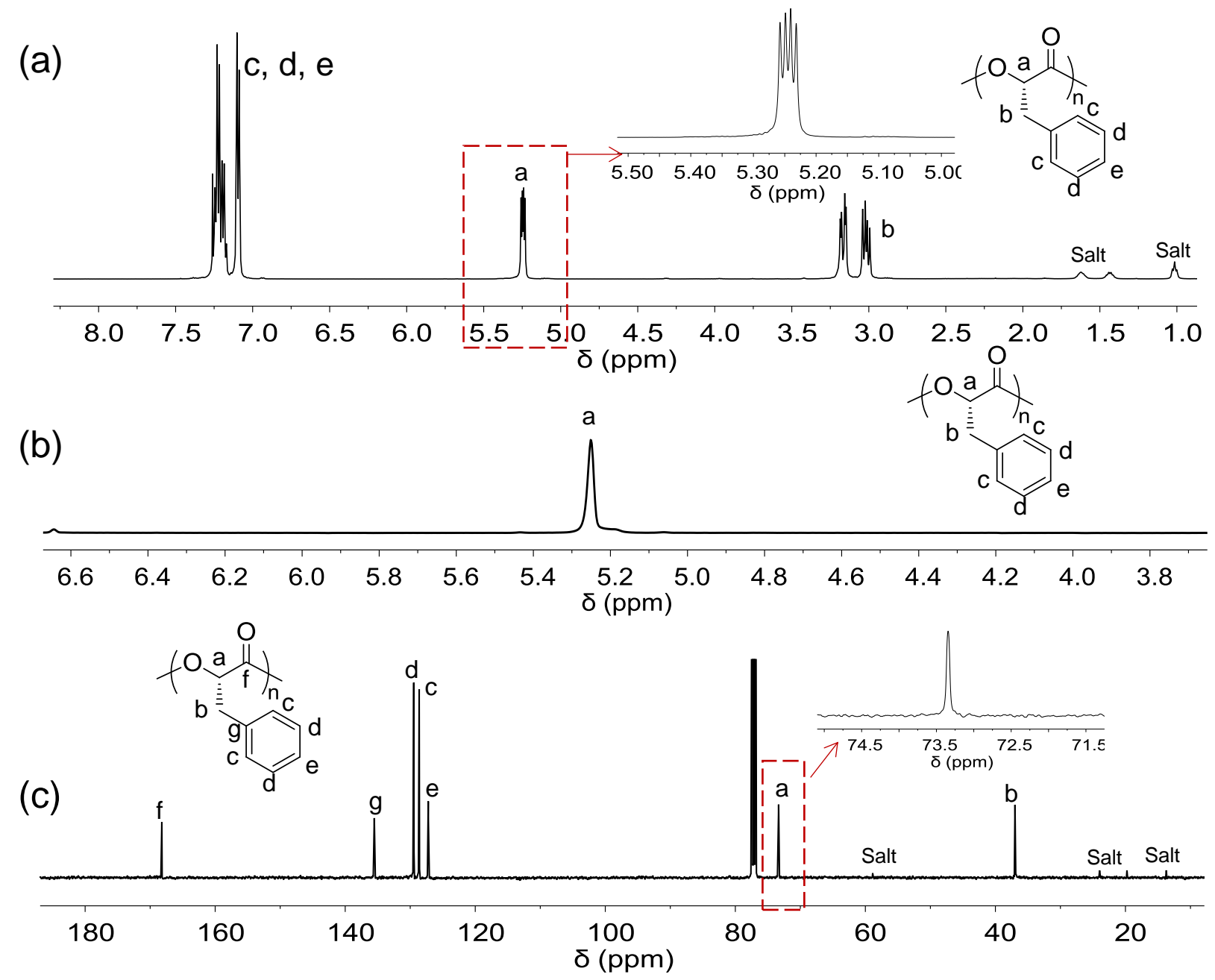

Figure S5. NMR spectra of poly(L-1) in $\mathrm{CDCl}_{3}$ (Table 1, entry 2). (a) ${ }^{1} \mathrm{H}$ NMR spectrum; (b) Homodecoupling ${ }^{1} \mathrm{H}$ NMR spectrum; (c) ${ }^{13} \mathrm{C}$ NMR spectrum. Note that the small shoulder peak in (b) is due to the NMR instrument. Both the well-split peak of $\alpha$-proton in (a) and single peak in $\alpha$-methine in (c) support that no epimerization occurs during the polymerization. 
(a) TBAH

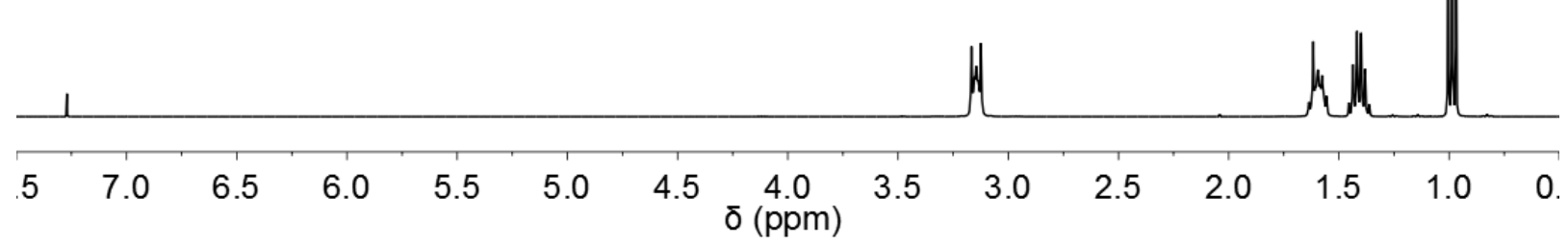

(b) TBAH / THF electrolysis, $4 \mathrm{~mA}, 1 \mathrm{~h}$

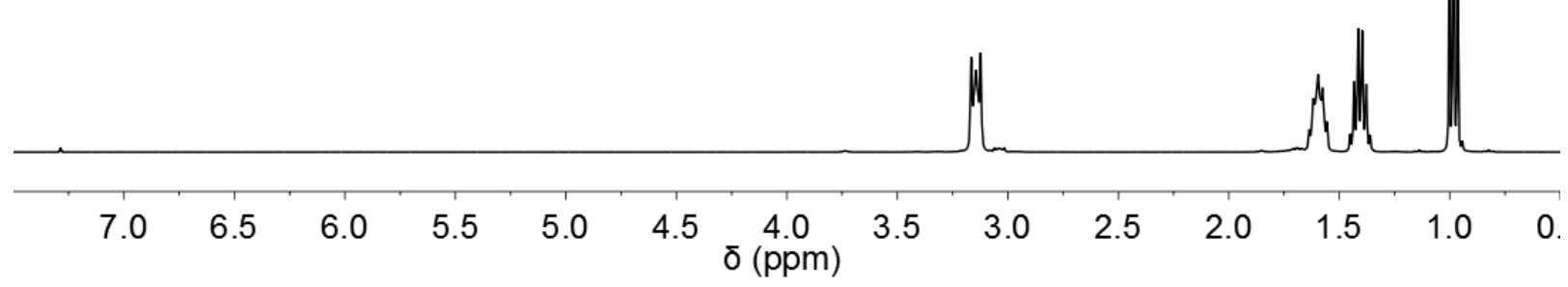

Figure S6. ${ }^{1} \mathrm{H}$ NMR spectra of (a) TBAH and (b) The mixture after electrolysis of $0.1 \mathrm{M}$ TBAH in THF solution using the electrochemical polymerization condition $(\mathrm{Mg}(+) / \mathrm{Pt}(-), 4 \mathrm{~mA}, 1$ hour) without adding the OCA monomer. Solvent: $\mathrm{CDCl}_{3}$. 

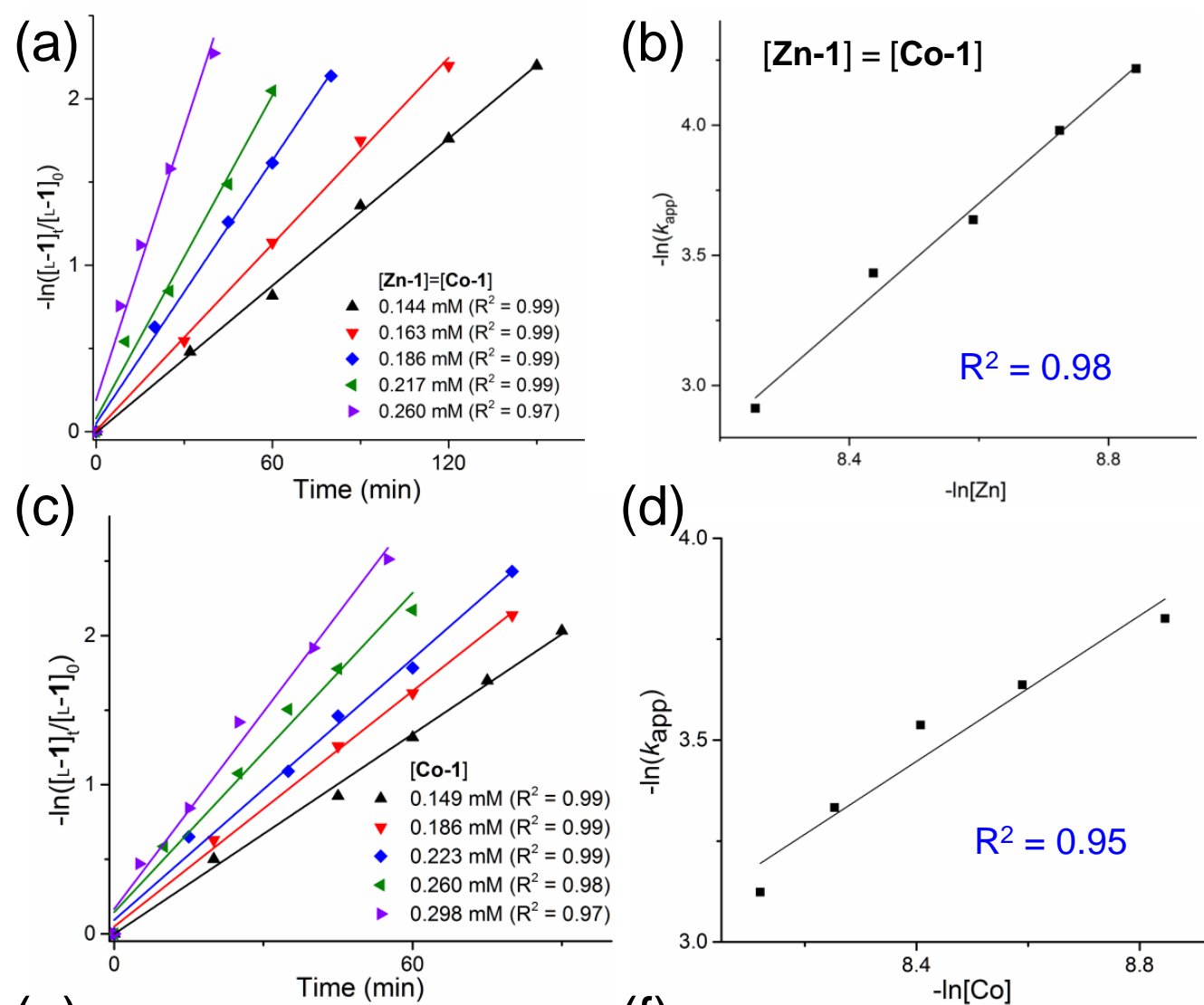

(e)
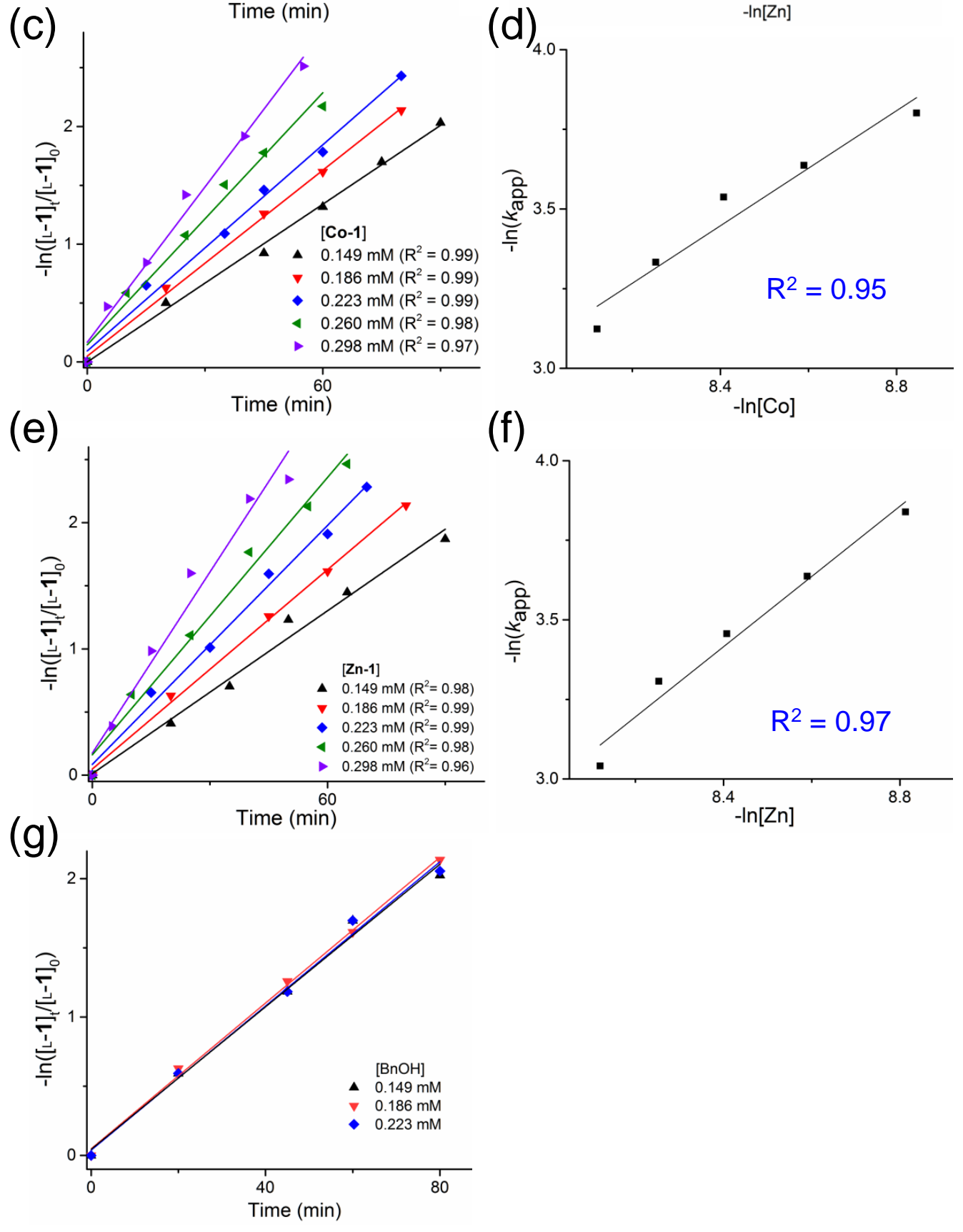
Figure S7. Kinetic plots of the electrochemical ROP of L-1 with variation of catalysts' concentrations at $0{ }^{\circ} \mathrm{C}$ using $\mathrm{Mg}(+) / \mathrm{Pt}(-)$ electrodes and $4 \mathrm{~mA}$ current. [L-1] $=130.2 \mathrm{mM}$ in all studies. (a) $[\mathbf{C o - 1}] /[\mathbf{Z n}-\mathbf{1}] /[\mathrm{BnOH}]=1 / 1 / 1$. (c, e, g) only the noted catalyst's concentration was changed and the rest is fixed at $0.186 \mathrm{mM}$ in THF. (b, d) Plot of $-\ln \left(k_{\mathrm{app}}\right)$ versus $-\ln$ [catalyst] for eROP of L-1. The slope of which suggests the reaction orders.

\section{Discussion:}

We fixed the $\mathrm{Co} / \mathrm{Zn}$ ratio at $1 / 1$ in the kinetic studies and found the reaction order was $2.16 \pm$ 0.13 (Figure S7b). This value is close to the sum of the individual reaction order of Co-1 (0.90 \pm 0.12 , Figure S7d) and Zn-1 (1.10 \pm 0.10, Figure S7f), which also suggested no formation of CoZn complex during the polymerization (supported by Figure S20). The propagation rate independence of $\mathrm{BnOH}$ indicates that $\mathrm{BnOH}$ only involved in the chain initiation (Figure $\mathrm{S} 7 \mathrm{~g}$ ). These results suggest that the kinetics of eROP of L-1 can be described by the equation:

$-\mathrm{d}[\mathrm{L}-\mathbf{1}] / \mathrm{d} t=k_{\mathrm{p}}[\mathbf{C o}-\mathbf{1}]^{0.90}[\mathbf{Z n - 1}]^{1.10}[\mathrm{~L}-\mathbf{1}]^{1}$

We listed reaction order as integers in the paper. Note that a few kinetic studies with fitted lines had y-intercept larger than zero, presumably due to the rapid kinetics and experimental error in the early time points (especially for reaction rates at $5 \mathrm{~min}$ and $10 \mathrm{~min}$ ). For higher feeding ratio reactions, the y-intercept values are zero. 
(a)

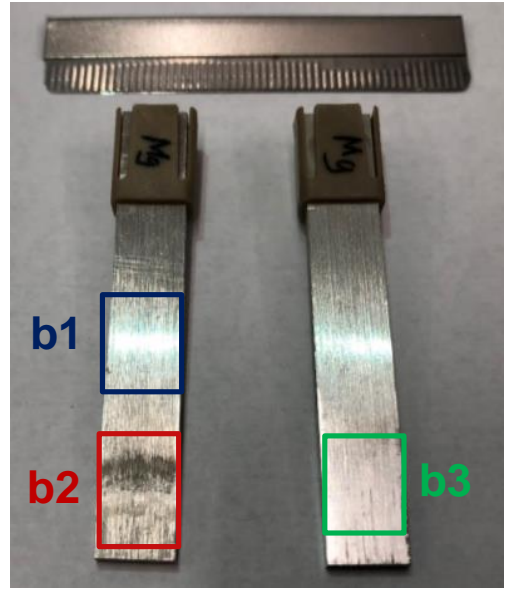

(b)

No reaction

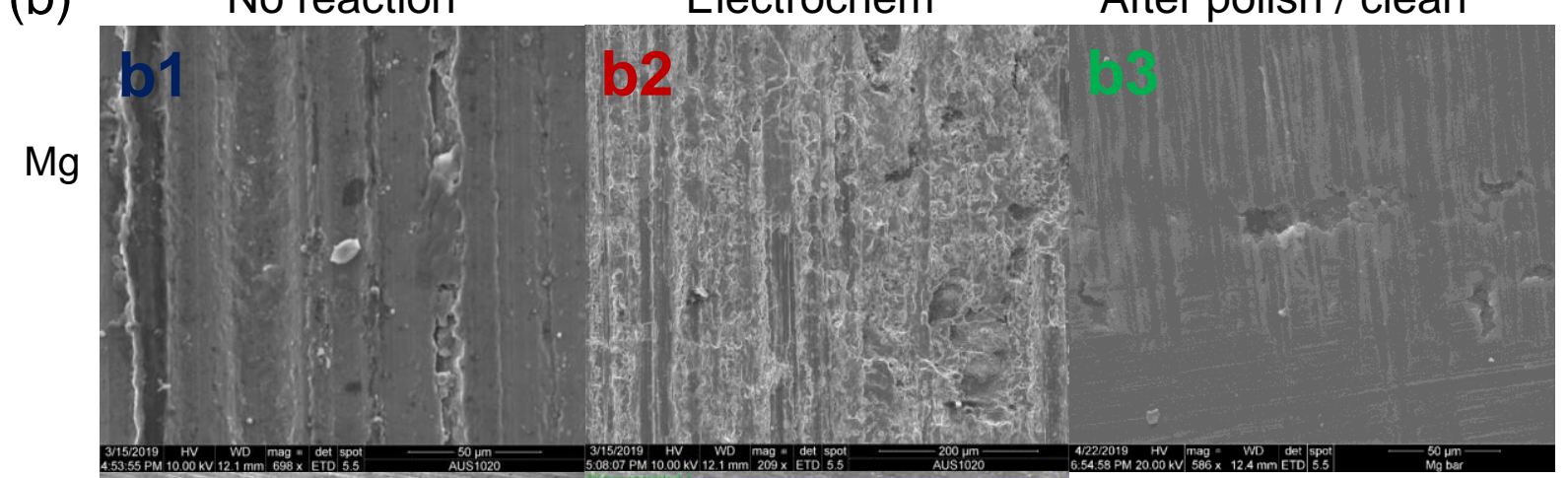

(c)

$\mathrm{Ni}$

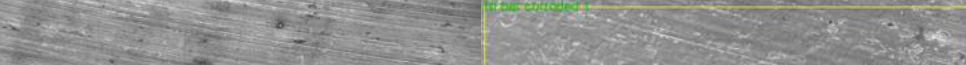

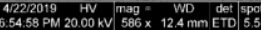

After polish / clean

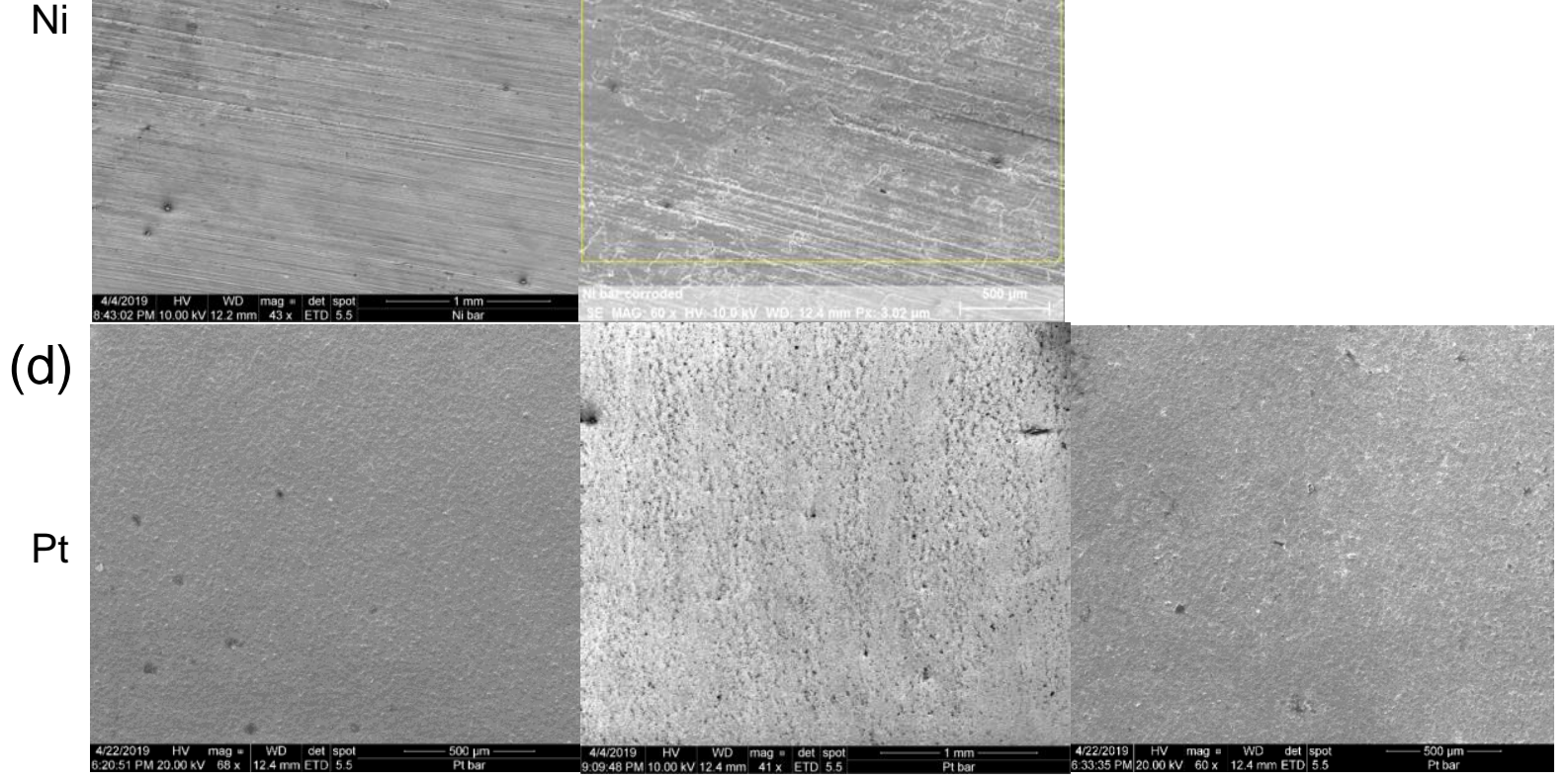




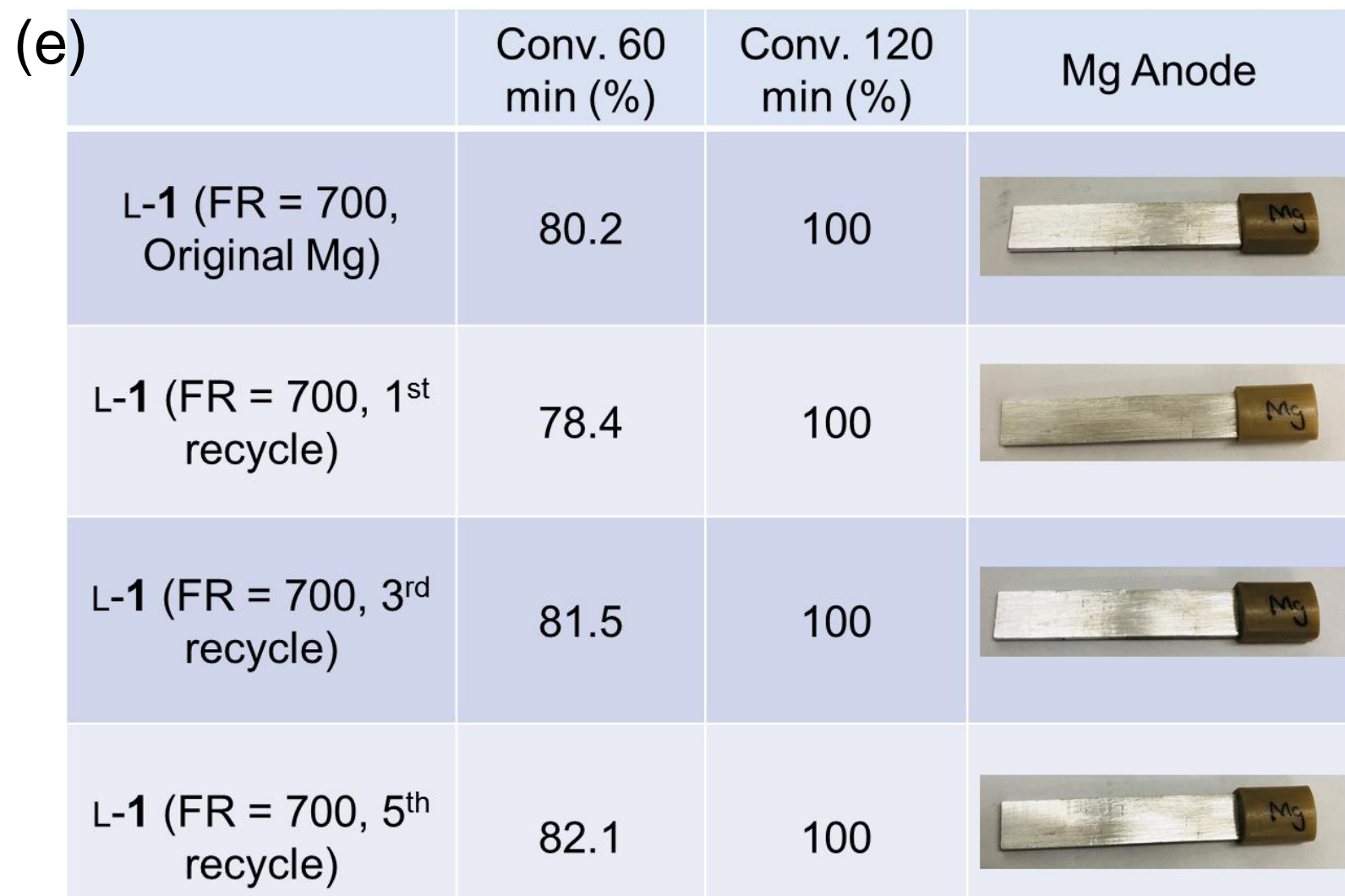

Figure S8. Characterizations of electrode surfaces before and after electrochemical polymerization, and after cleaning. (a) $\mathrm{Mg}$ electrodes after electrochemical polymerization and after cleaning. The deposited salt in the Mg electrode surfaces can be scraped and cleaned. Scanning electron microscopies of (b) $\mathrm{Mg}$, (c) $\mathrm{Ni}$ and (d) Pt electrode surfaces in the conditions of no reaction, after eROP and scraping/cleaning of the surface. (e) Repetitive recycling / cleaning of $\mathrm{Mg}$ anode does not affect polymerization kinetic rates. 
(a) Control

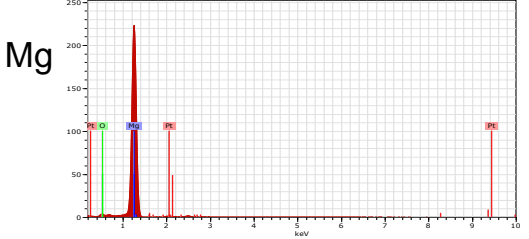

spectrum: GF6

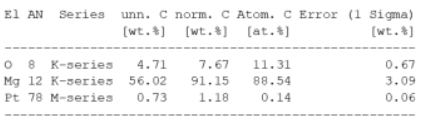

Total: $61.46 \quad 100.00 \quad 100.00$

(b)
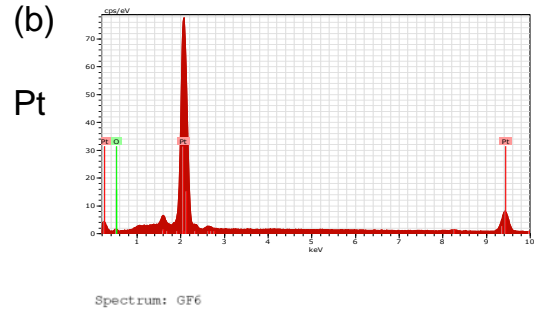

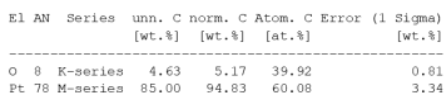

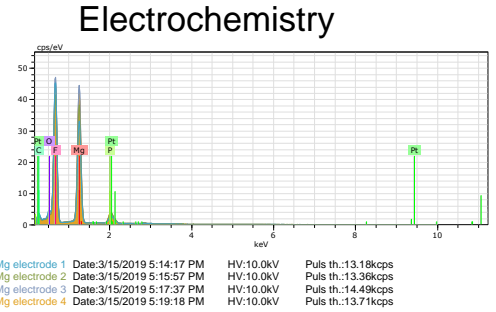

Atomic percent
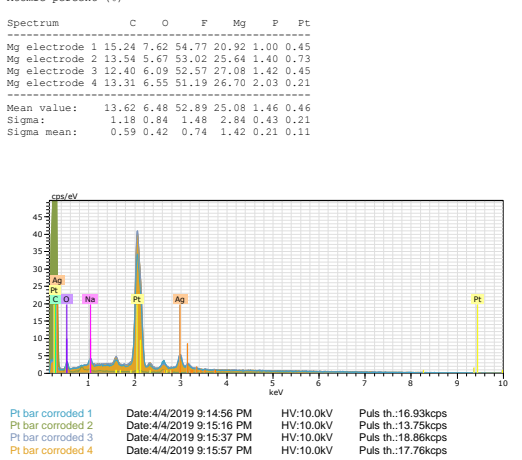

Atomic per

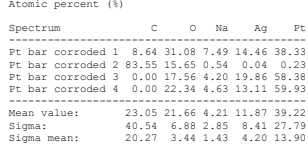

$4 / 4 / 2019$

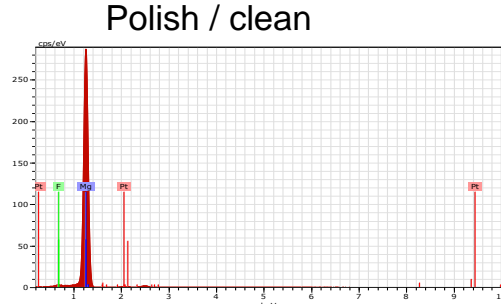

spectrum: GF6
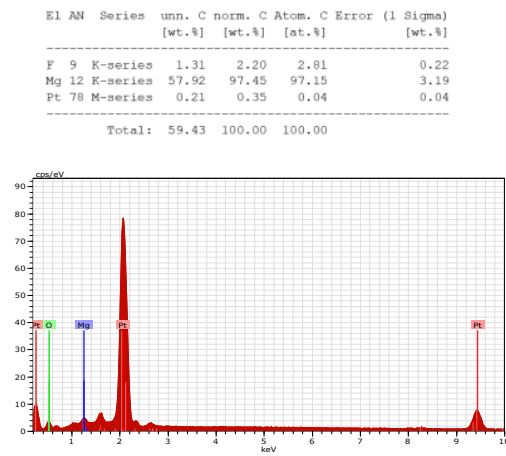

Spectrum: GF6

B1 AN Series unn. C norm. C Atom. C Error (1 sigma)

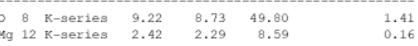

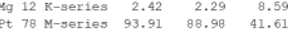

Fotal: $105.55 \quad 100.00 \quad 100.00$

Figure S9. Energy-dispersive X-ray spectroscopies analysis of the elements on the electrode surfaces that are shown in Figure S8. Three conditions correspond to no reaction (b1), after electrochemical polymerization (b2) and after scraping/cleaning of the surface (b3) in Figure S8. The results confirmed that majority of TBAH salt can be removed from Mg anode surface as $\mathrm{F}$ atom $\%$ decreased from $52.89 \%$ to $2.81 \%$, accompanied by the absence of $\mathrm{P}$ and $\mathrm{C}$ after cleaning. The 8.59 atom $\%$ of $\mathrm{F}$ may suggest the possible diffusion of $\mathrm{Mg}$ from anode to cathode surface. Both Pt and Mg electrodes can be recycled for repetitive polymerization studies without affecting the polymerization results (see Table 1 entry 8). 

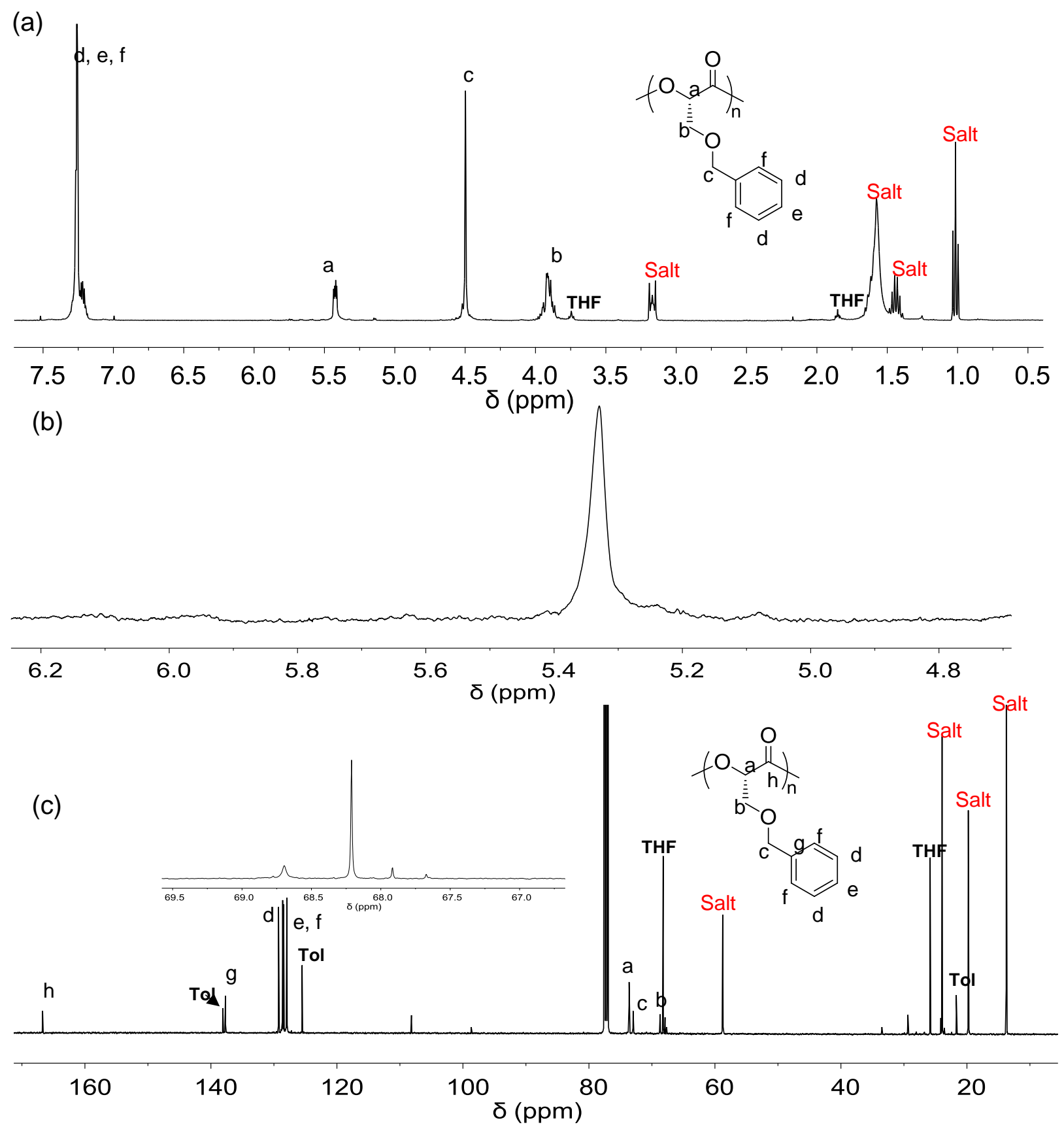

Figure S10. NMR spectra of poly(L-2) in $\mathrm{CDCl}_{3}$. (a) ${ }^{1} \mathrm{H}$ NMR spectrum; (b) Homodecoupling ${ }^{1} \mathrm{H}$ NMR spectrum; (c) ${ }^{13} \mathrm{C}$ NMR spectrum. 

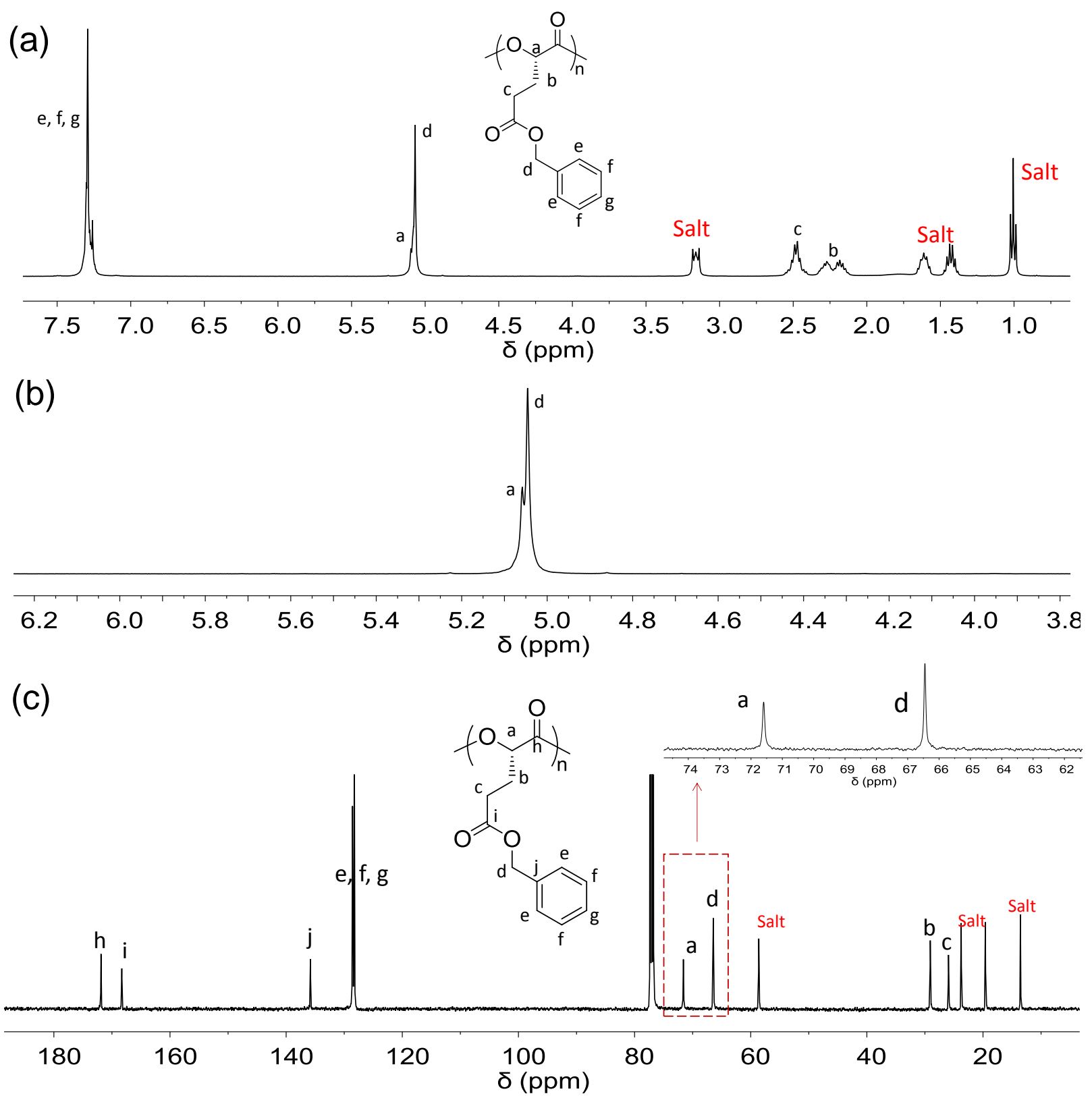

Figure S11. NMR spectra of poly(L-3) in $\mathrm{CDCl}_{3}$. (a) ${ }^{1} \mathrm{H}$ NMR spectrum; (b) Homodecoupling ${ }^{1} \mathrm{H}$ NMR spectrum; (c) ${ }^{13} \mathrm{C}$ NMR spectrum. 


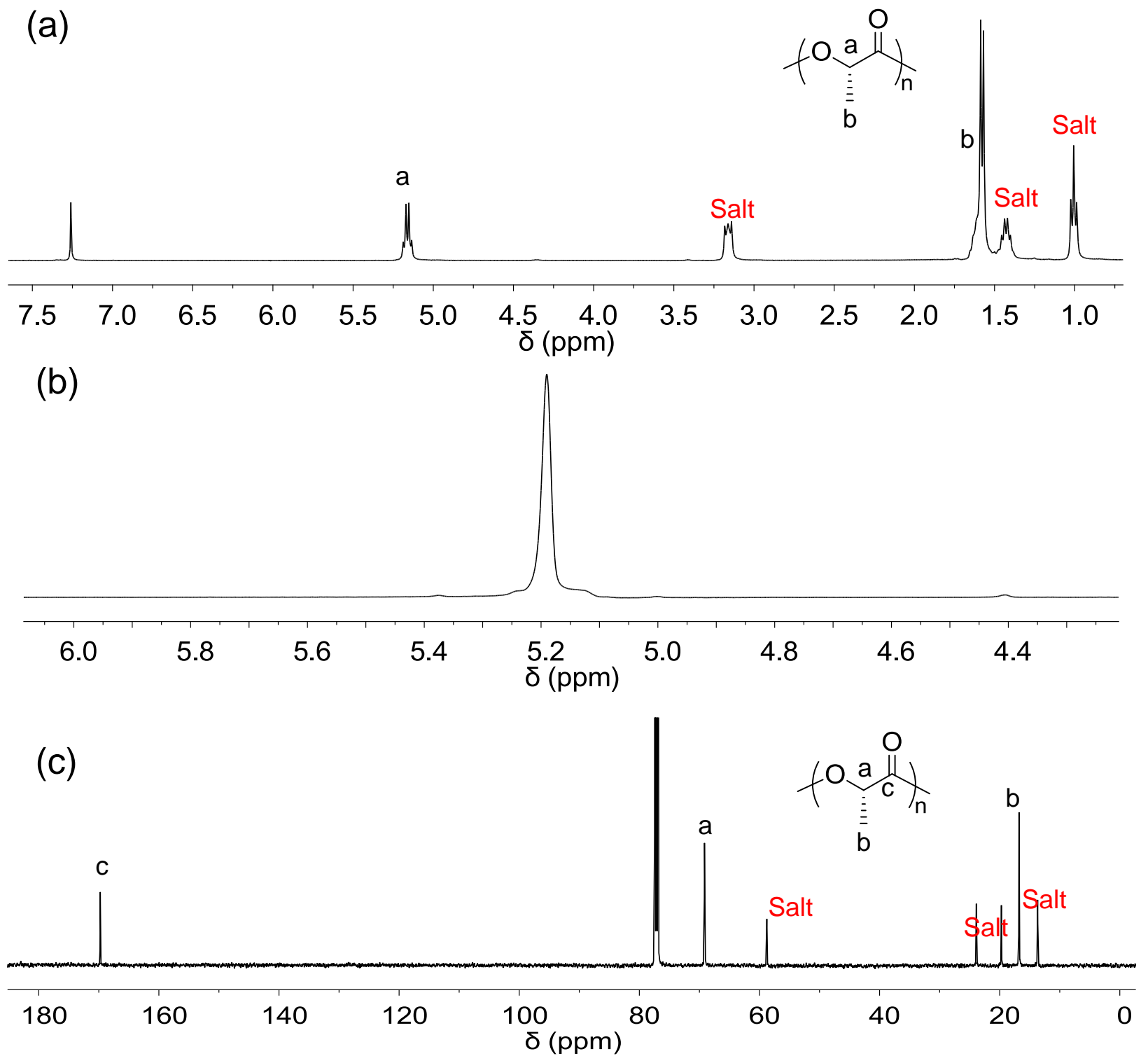

Figure S12. NMR spectra of poly(L-4) in $\mathrm{CDCl}_{3}$. (a) ${ }^{1} \mathrm{H}$ NMR spectrum; (b) Homodecoupling ${ }^{1} \mathrm{H}$ NMR spectrum; (c) ${ }^{13} \mathrm{C}$ NMR spectrum. 


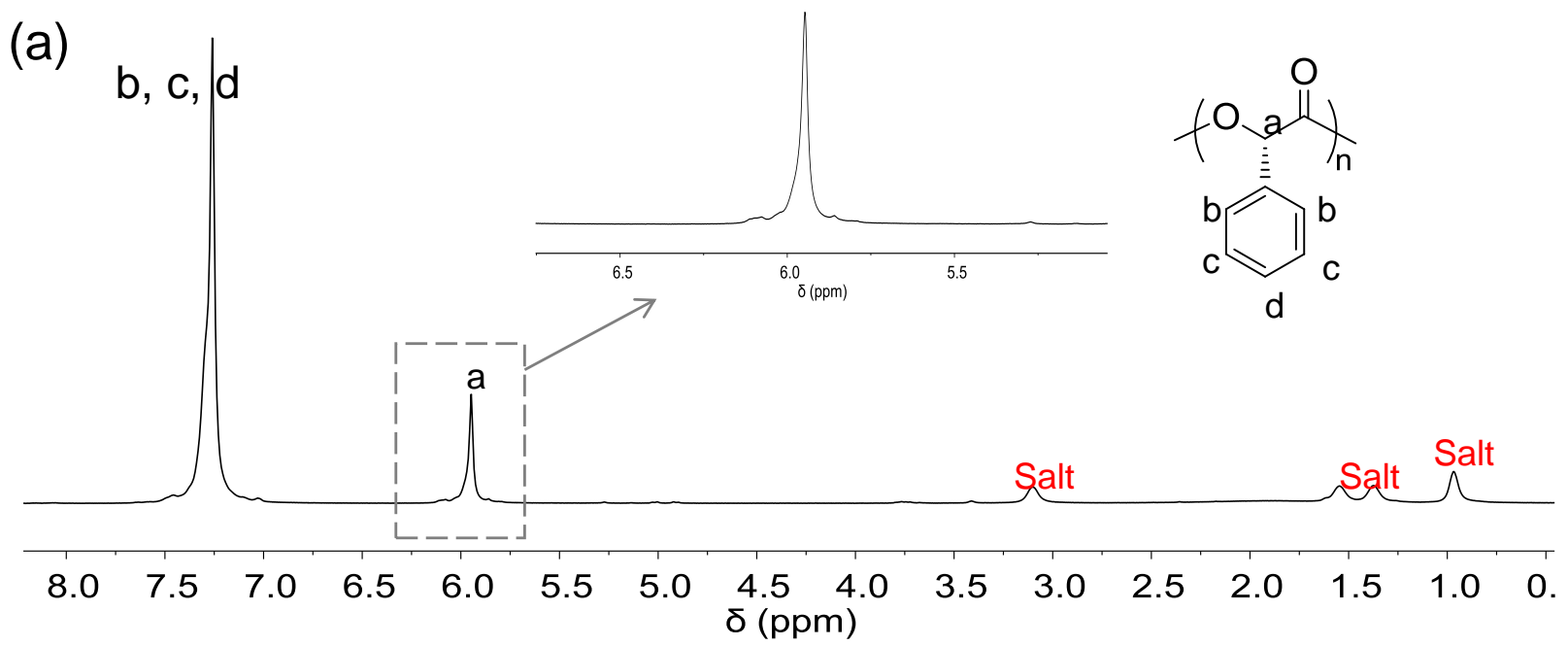

(b)

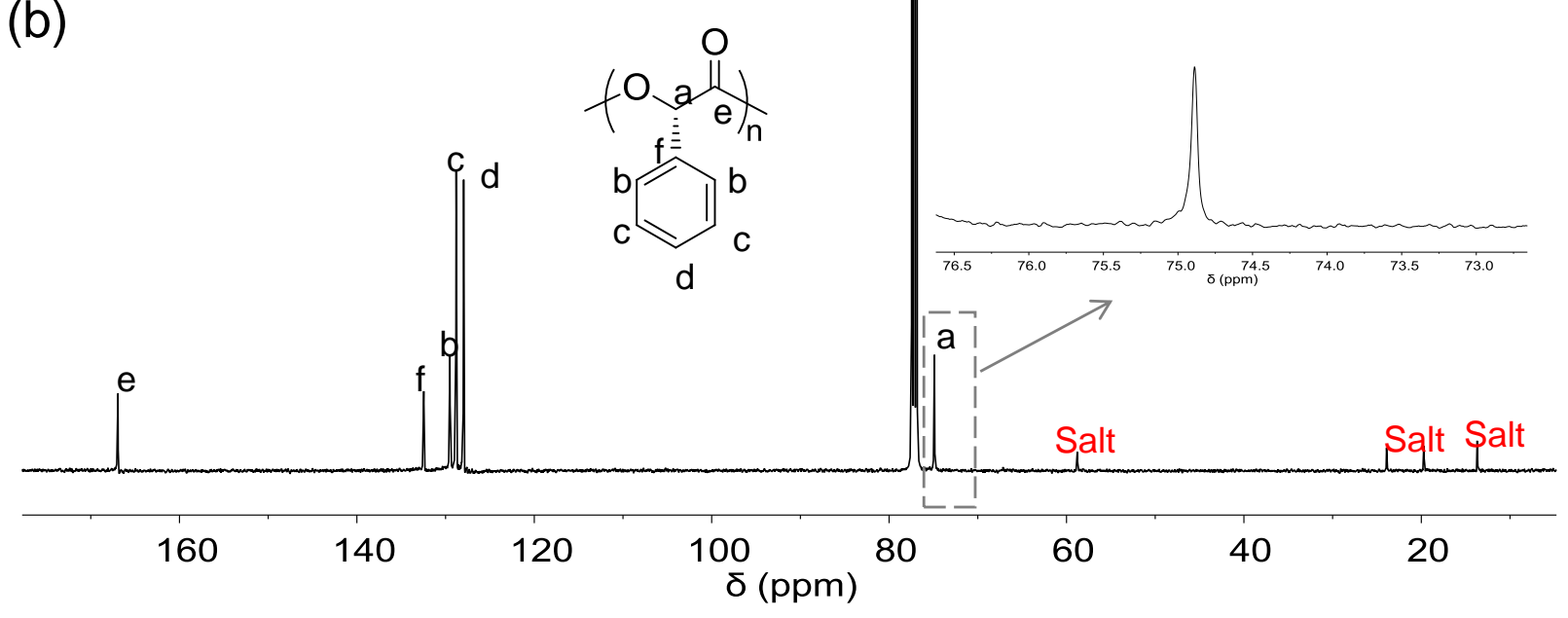

Figure S13. NMR spectra of poly(L-5) in $\mathrm{CDCl}_{3}$. (a) ${ }^{1} \mathrm{H}$ NMR spectrum; (b) ${ }^{13} \mathrm{C}$ NMR spectrum. 

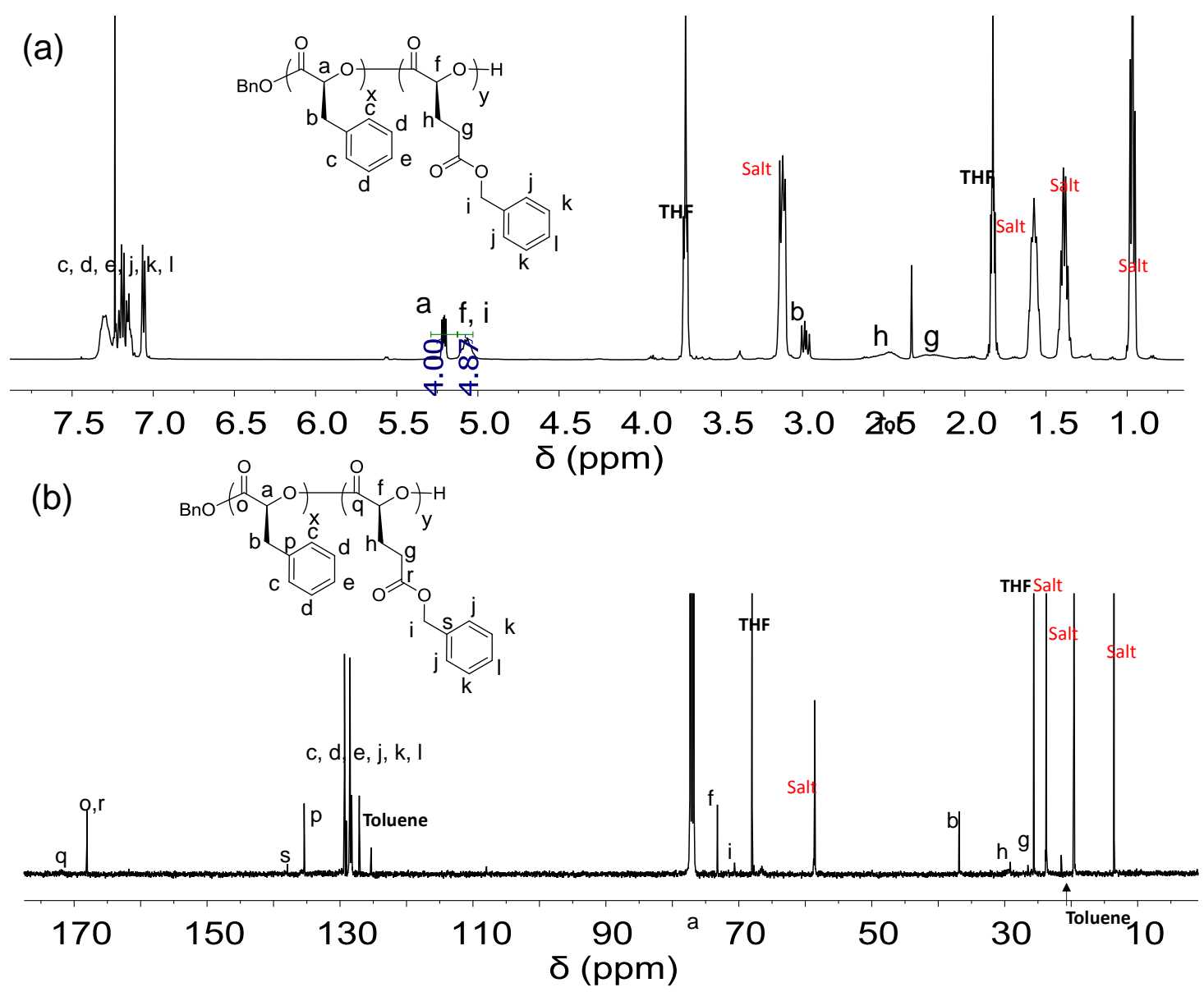

(c)
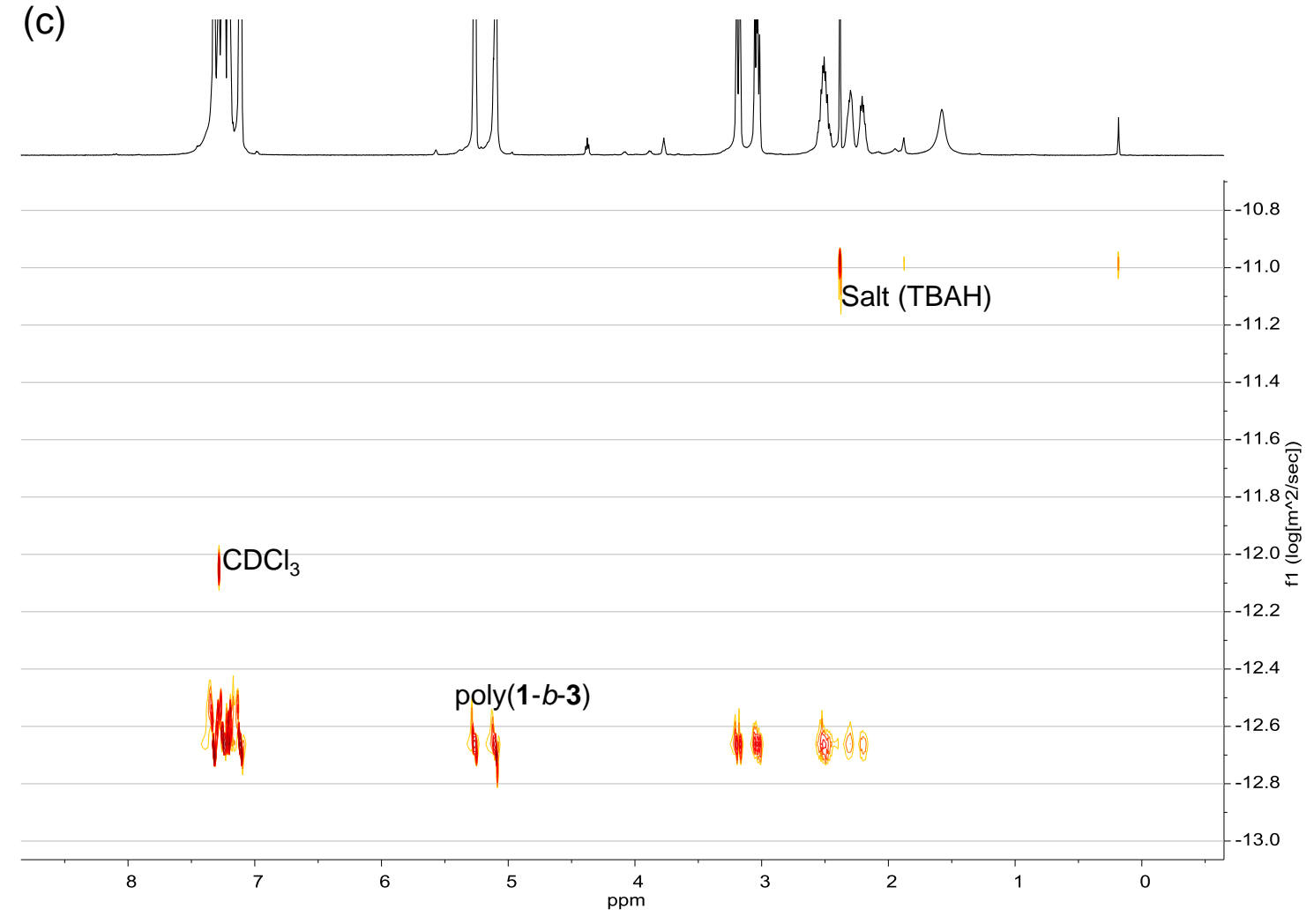
Figure S14. NMR spectra of poly(L-1-b-L-3) in $\mathrm{CDCl}_{3}$. (a) ${ }^{1} \mathrm{H}$ NMR spectrum; (b) ${ }^{13} \mathrm{C}$ NMR spectrum; (c) ${ }^{1} \mathrm{H}$ - DOSY (diffusion ordered spectroscopy) spectrum, which confirms the formation of block copolymer. 
(a)

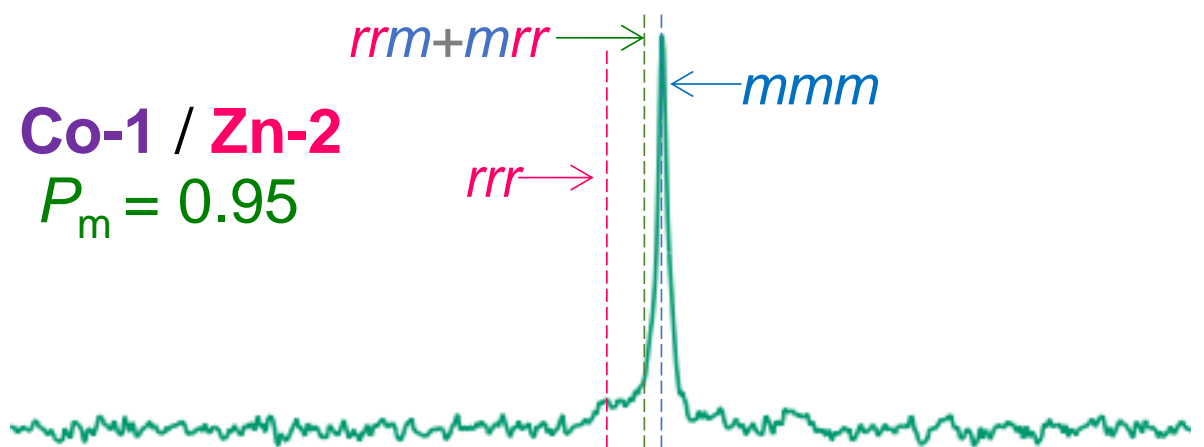

(b) Co-2 / Zn-3

$P_{\mathrm{r}}=0.79$

(c) Co-1/Zn-3

$P_{\mathrm{m}}=0.62$

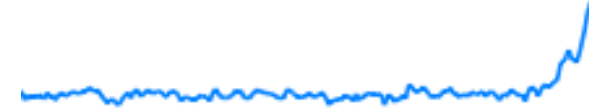

$$
P_{\mathrm{m}}=0.62
$$

Co-2 / Zn-2

(d) Co-2 / Zn-
$P_{\mathrm{m}}=0.58$
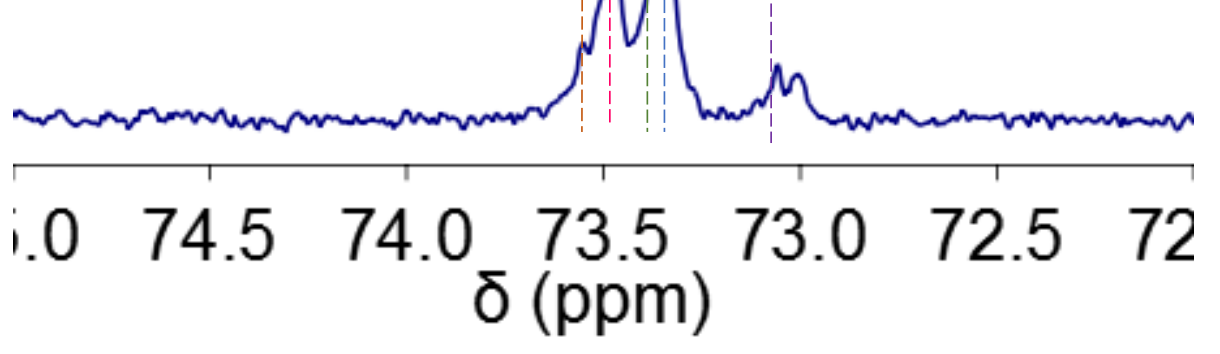

Figure S15. ${ }^{13} \mathrm{C}$ NMR spectra overlay of electrochemical stereoselective ring-opening polymerization of rac-1. Note that we used ${ }^{13} \mathrm{C}$ NMR spectra for $P_{\mathrm{m}}$ calculation as the homodecoupled ${ }^{1} \mathrm{H}$ NMR spectra did not present good resolution for polymers with $P_{\mathrm{m}}$ values lower than 0.9 . 

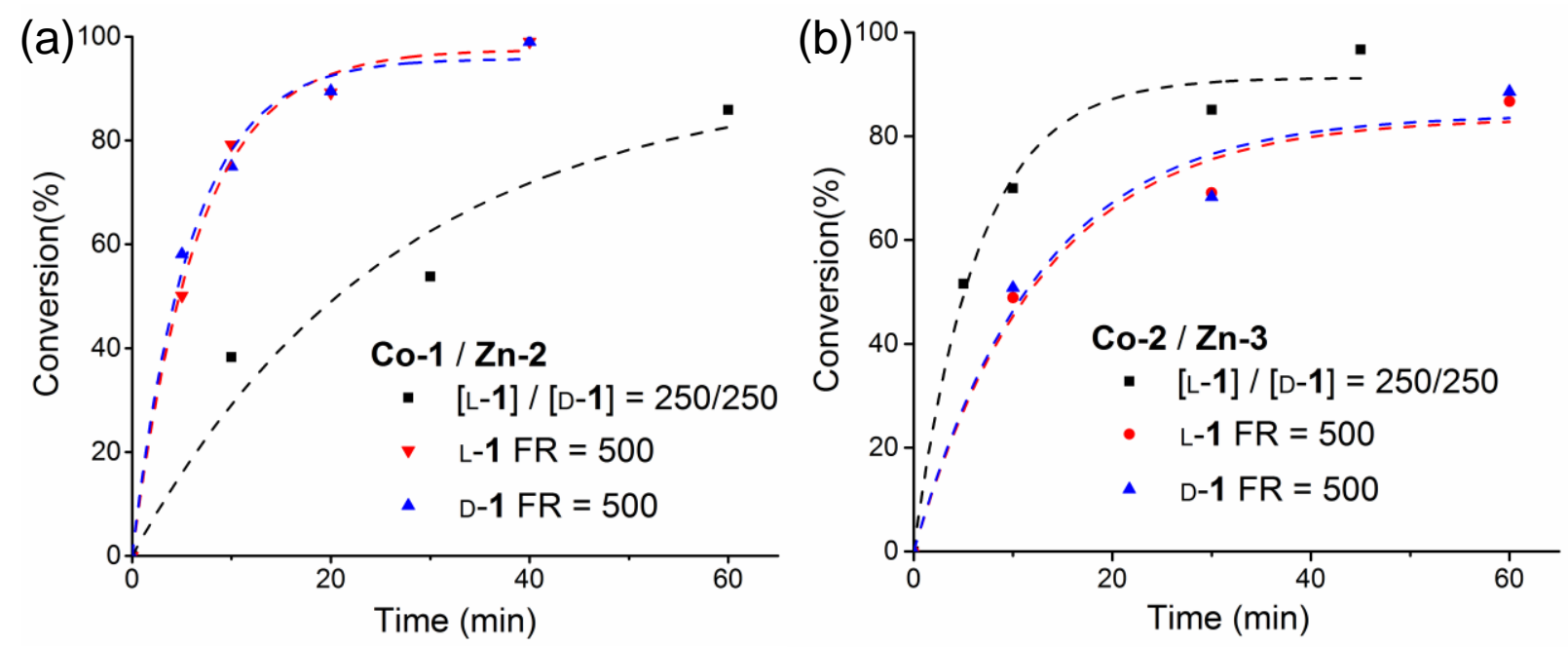

Figure S16. Plots of monomer conversion in polymerization reactions of (a) L-1 ([L-1 $] /[\mathbf{Z n -}$ 2]/[Co-1] $/[\mathrm{BnOH}]=500 / 1 / 1 / 1), \mathrm{D}-\mathbf{1}([\mathrm{D}-\mathbf{1}] /[\mathbf{Z n - 2}] /[\mathbf{C o - 1}] /[\mathrm{BnOH}]=500 / 1 / 1 / 1)$, and $\mathrm{rac}-\mathbf{1}([\mathrm{L}-$ 1]/[D-1]/[Zn-2]/[Co-1]/[BnOH] = 250/250/1/1/1), [1] = $130.2 \mathrm{mM;} \mathrm{(b)} \mathrm{L-1} \mathrm{([L-1]/[Zn-3]/[Co-2]}$ $=500 / 1 / 1)$, D-1 $([\mathrm{D}-\mathbf{1}] /[\mathbf{Z n}-\mathbf{3}] /[\mathbf{C o}-2]=500 / 1 / 1)$, and $r a c-1([\mathrm{~L}-\mathbf{1}] /[\mathrm{D}-\mathbf{1}] /[\mathbf{Z n}-\mathbf{3}] /[\mathbf{C o}-2]=$ 250/250/1/1), [1] = $130.2 \mathrm{mM}$.

\section{Discussion:}

The results in (b) showed that the polymerization of $r a c-\mathbf{1}$ mediated by $\mathbf{C o - 2} / \mathbf{Z n}-\mathbf{3}$ had more rapid polymerization rate than that of each enantiomer, which indicated the syndioselective polymerization of $r a c-1$. On the other hand, for isoselective polymerization mediated by Co$\mathbf{1} / \mathbf{Z n - 2}$, the copolymerization rate was significantly slower than that of each enantiomer.

Based on Figures S15 and S16, we conclude that Co/Zn-mediated stereoselective eROPs are likely exerted by chain end control mechanism. For eROPs of $r a c-\mathbf{1}$ and $r a c-\mathbf{4}$ mediated by Co$\mathbf{1 / Z n - 2}$, our reported work on $\mathbf{Z n - 2}{ }^{14}$ suggested the isoselective chain end control mechanism. For eROP of $r a c-\mathbf{1}$ mediated by $\mathbf{C o - 2 / Z n - 3 , ~ r m r ~ p e a k ~ a r e a ~ i s ~ l a r g e r ~ t h a n ~ t h a t ~ o f ~} r m m$ or $m m r$, suggesting the syndioselective chain end control mechanism.

We also calculated the average sequence length in poly $(s b-\mathbf{1})$ mediated by Co-1/Zn-2 using Randall's equation:

$n(m)=\left(I_{r r r}+1 / 2 I_{r r m}+2 I_{r m r}+3 / 2 I_{m m r}+I_{m m m}\right) /\left(I_{r r r}+1 / 2 I_{r r m}+I_{r m r}+1 / 2 I_{m m r}\right)$

where $I_{m m r}, I_{m m m}$, and so on are the respective NMR areas. ${ }^{18}$ The poly $(s b-1)$ contained an average of 11 units $(n(m))$ of enantiomerically pure 1. Similarly, we also calculated the average syndiotactic sequence length in poly $(s d-\mathbf{1})$ mediated by Co-2/Zn-3, following $n(r)=1 /\left(1-P_{\mathrm{r}}\right)$, where assuming Bernoullian chains. The poly $(s d-\mathbf{1})$ contained an average of 5 units $(n(r))$ of racemic 1. 
(a)

$\operatorname{poly}(s b-1)$ by $\mathrm{Co-1/Zn-2}$

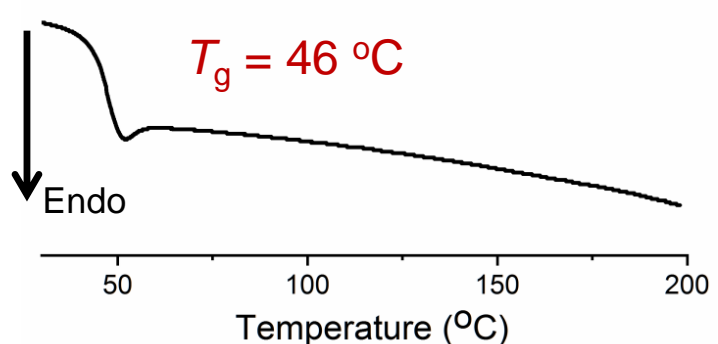

(c) poly(L-5)

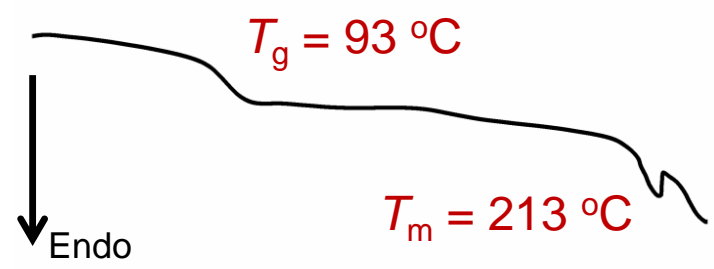

\begin{tabular}{cccc}
\hline 50 & 100 & 150 & 200 \\
& Temperature $\left({ }^{\circ} \mathrm{C}\right)$ &
\end{tabular}

(e) poly (sb-4) by Co-1/Zn-2

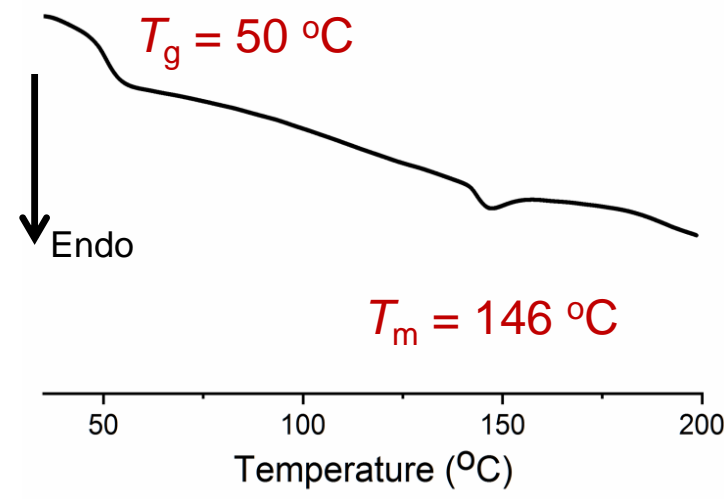

(b)

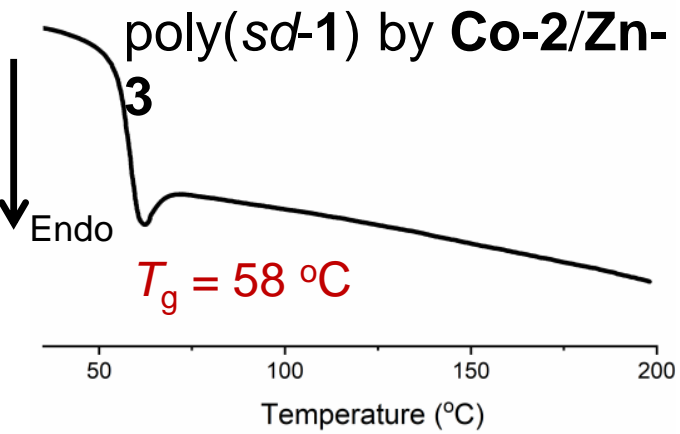

(d) $\operatorname{poly}(s b-3)$ by $\mathrm{Co-1/Zn-2}$

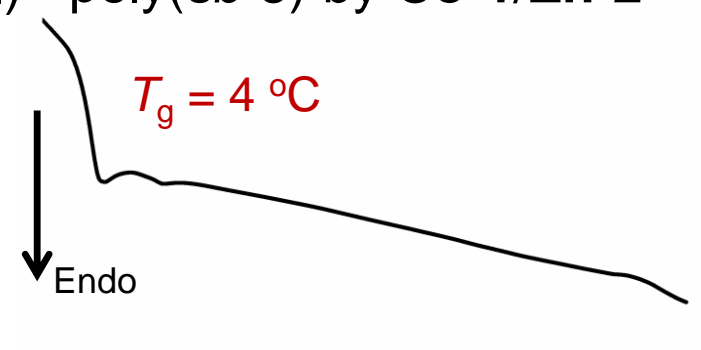

(f) $\operatorname{poly}(s b-4)$ by Co-2/Zn-3

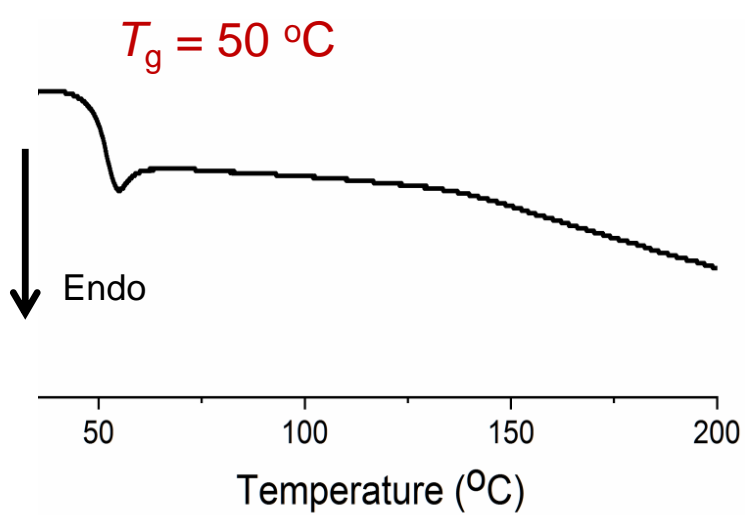

Figure S17. DSC thermograms of polyesters with various microstructures. Details of polymers' MWs and Đs are shown, respectively, in (a) Table 2, entry 1; (b) Table 2, entry 2; (c) Table S8 entry 10; (d) Table 2, entry 3; (e) Table 2, entry 4; (f) Table 2, entry 5.

\section{Discussion:}

Note that our previous studies showed that poly(L-1) had a $T_{\mathrm{g}}$ of $50{ }^{\circ} \mathrm{C}$, and poly $(\mathrm{rac}-\mathbf{1})$ had a $T_{\mathrm{g}}$ of $51{ }^{\circ} \mathrm{C} .{ }^{14}$ Neither polymer has a $T_{\mathrm{m}}$. The $T_{\mathrm{m}}$ peak exhibited in poly(L-5) indicated the stereoregularity and no epimerization occurred during the polymerization. Poly $(s b-4)$ synthesized 
by Co-1/Zn-2 had a $T_{\mathrm{m}}$ peak of $146{ }^{\circ} \mathrm{C}$, which was absent in that by $\mathbf{C o - 2 / Z n - 3}$, presumably due to the difference in their $P_{\mathrm{m}}$ values (see Table $\mathrm{S} 9$ ). Note that both had same $T_{\mathrm{g}}$ values. 


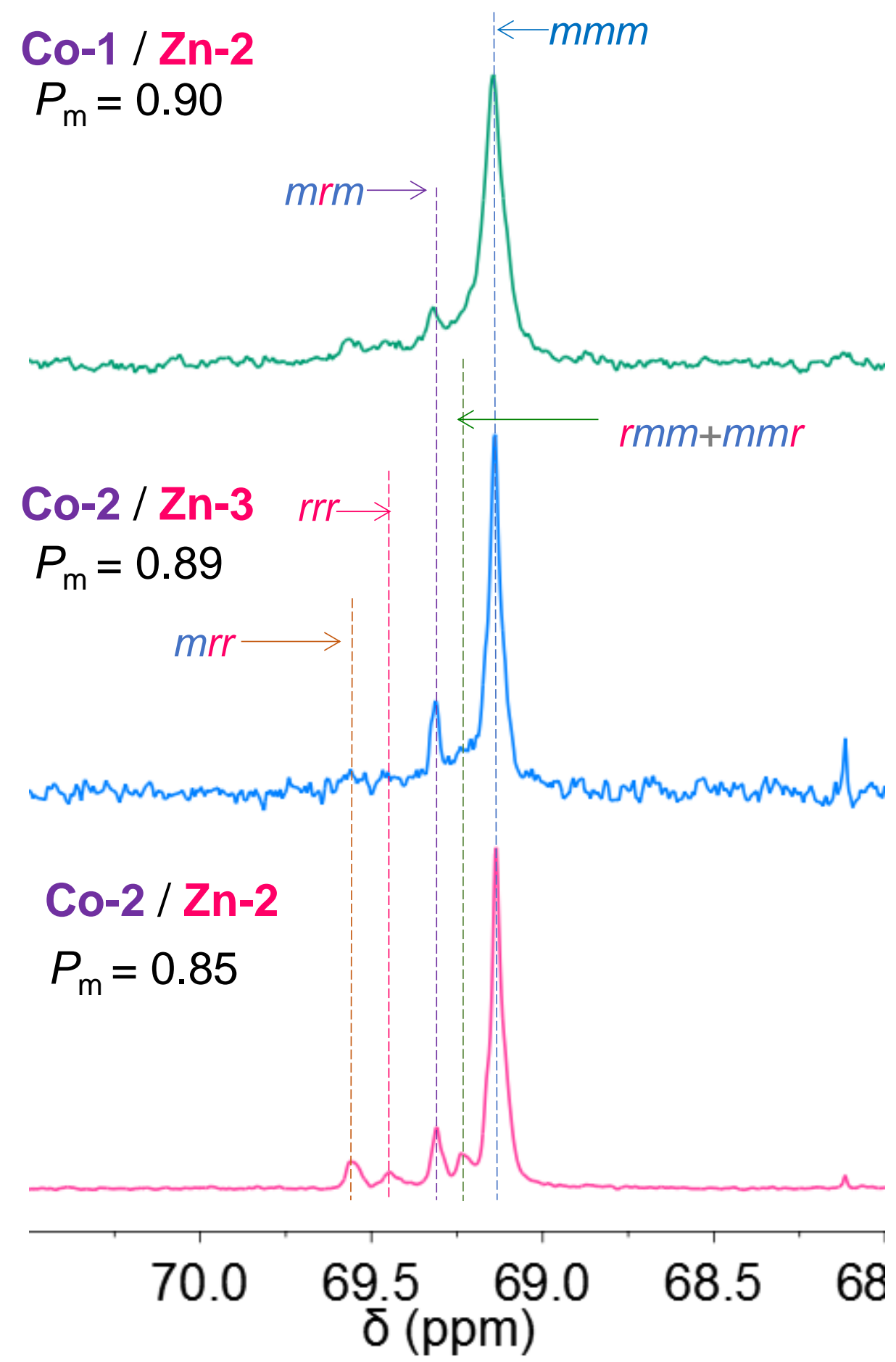

Figure S18. ${ }^{13} \mathrm{C}$ NMR spectra overlay of electrochemical isoselective ring-opening polymerization of rac-4. 


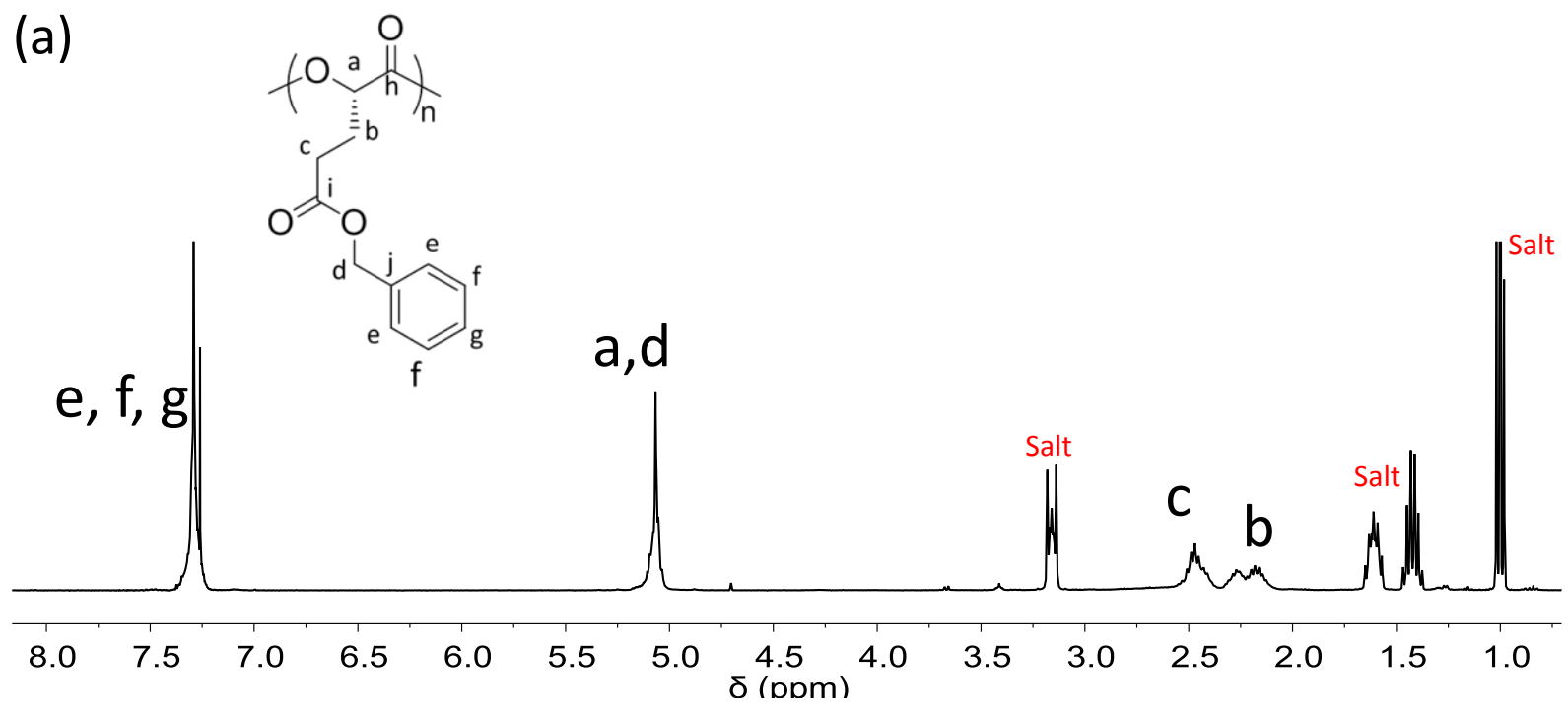

(b)

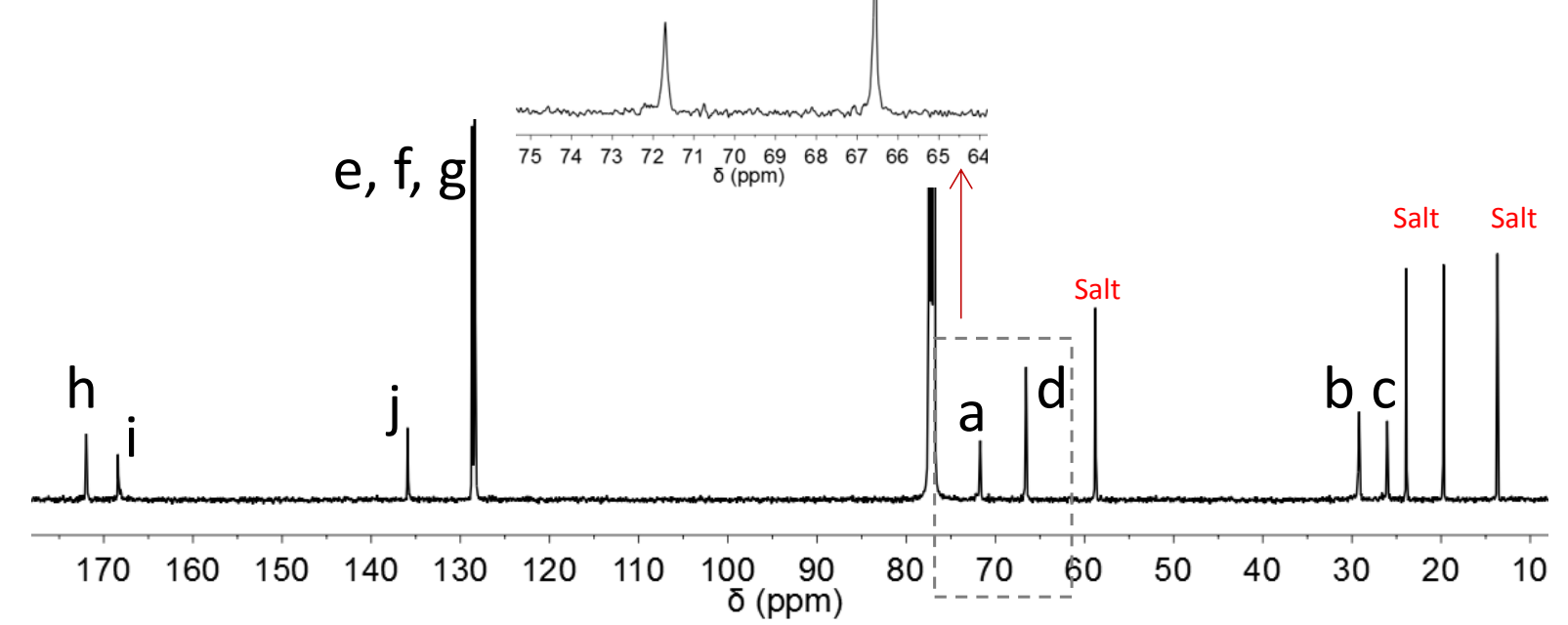

Figure S19. NMR spectra of poly $(s b-3)$ in $\mathrm{CDCl}_{3}$ prepared by $\mathbf{C o - 1 / Z n - 2}$ (Table 2 entry 3). (a) ${ }^{1} \mathrm{H}$ NMR spectrum; (b) ${ }^{13} \mathrm{C}$ NMR spectrum. 


\section{(a) Zn-1}
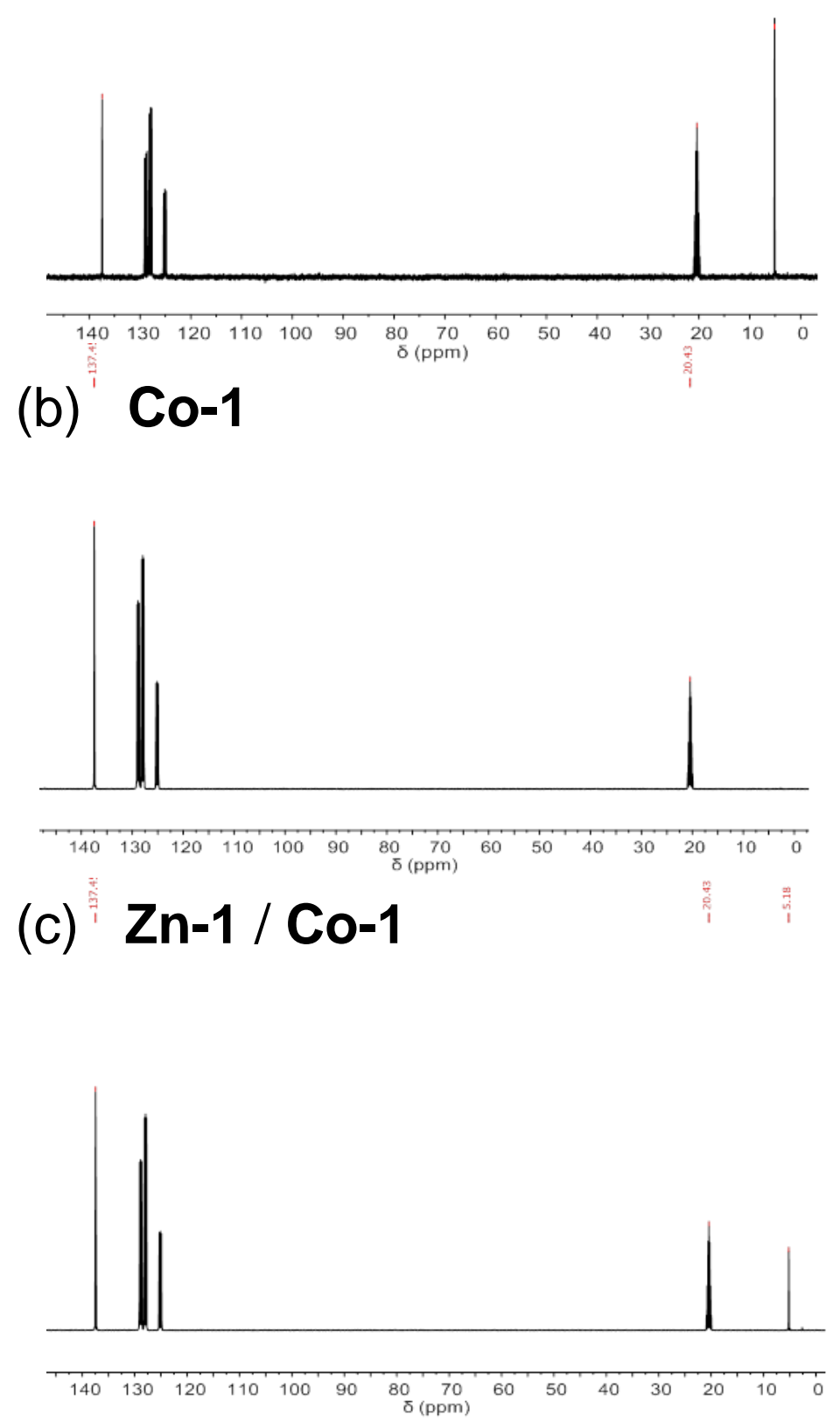

Figure S20. ${ }^{13} \mathrm{C}$ NMR spectra of Co-1, Zn-1 and their mixture (1/1) in toluene-d8. The results indicate no interaction between $\mathrm{Co}$ and $\mathrm{Zn}$ complexes.

\section{Discussion:}


Co-1 is paramagnetic and we did not expect to see any signal. If Co-1 formed any complexation with Zn-1, peaks could have changed in NMR spectra in (c), which were not observed in our study. This indicated that Co-1 and Zn-1 did not form complex in the absence of OCA. 


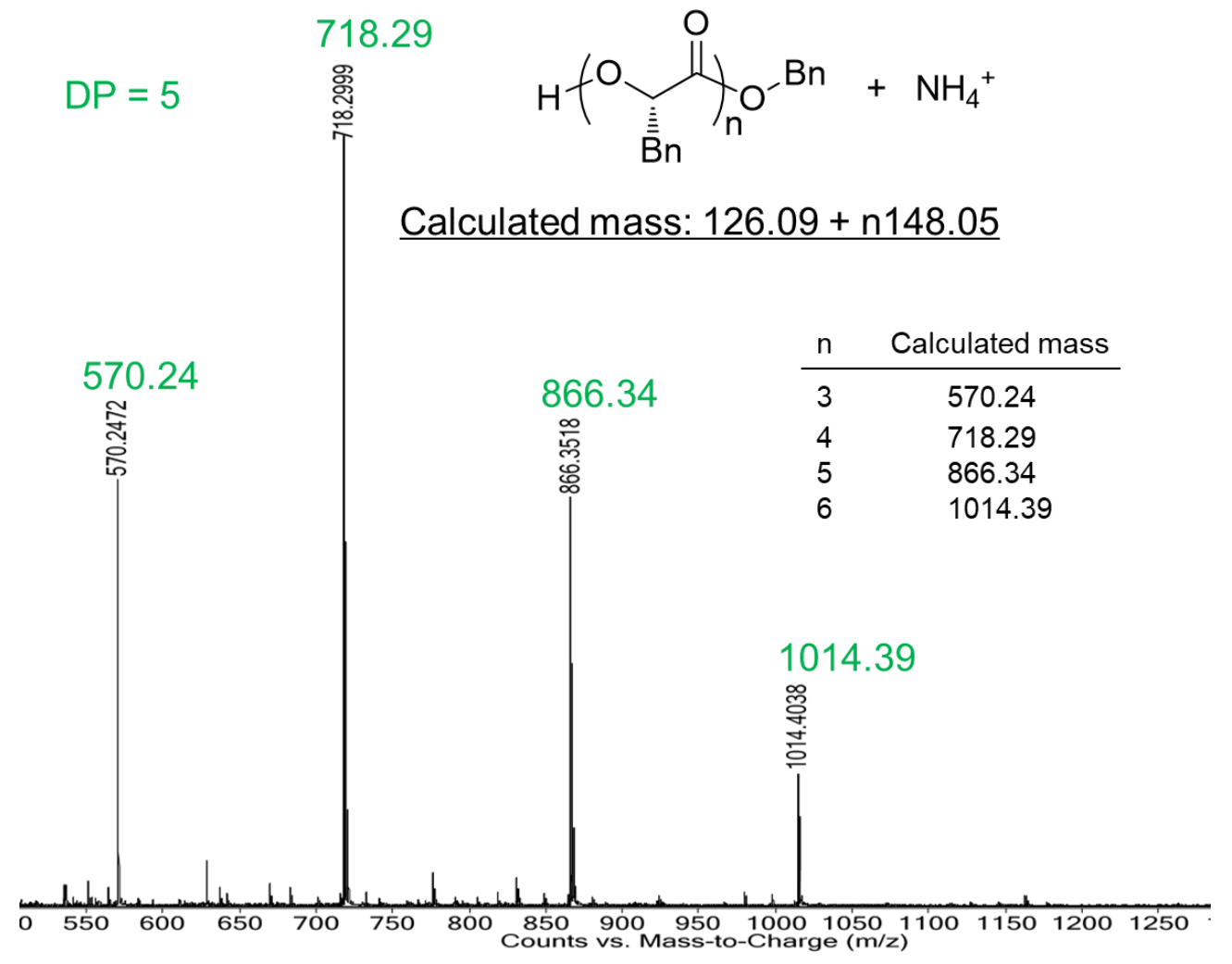

Figure S21. ESI-MS spectrum of oligo(L-1 $)_{5}$ initiated by $\mathbf{C o - 1 / Z n - 1 / B n O H}$ at $0{ }^{\circ} \mathrm{C}$ under photoredox condition (same as reaction condition in Table S1, [1] / [Co-1] / [Zn-1] / $[\mathrm{BnOH}]=5 / 1 / 1 / 1)$. The green color numbers indicated the calculated molecular weights for corresponding peaks.

\section{Discussion:}

High resolution ESI-MS results:

$\mathrm{n}=3 \mathrm{C}_{34} \mathrm{H}_{36} \mathrm{NO}_{7}$ : calculated, 570.2497; obtained, 570.2472.

$\mathrm{n}=4 \mathrm{C}_{43} \mathrm{H}_{44} \mathrm{NO}_{9}$ : calculated, 718.3016; obtained, 718.2999.

$\mathrm{n}=5 \mathrm{C}_{52} \mathrm{H}_{52} \mathrm{NO}_{11}$ : calculated, 866.3540; obtained, 866.3518.

$\mathrm{n}=6 \mathrm{C}_{61} \mathrm{H}_{60} \mathrm{NO}_{13}$ : calculated, 1014.4065; obtained, 1014.4038.

Note that we used the photoredox reaction condition to confirm that $\mathrm{BnO}$ - was at the chain terminus. The oligomer is difficult to separate from salt for ESI-MS analysis in the eROP condition. Results in Table 1 entry 6 also suggested the necessity of $\mathrm{BnOH}$ in the eROP reaction. 


\section{S6. References}

(1) Yin, Q.; Tong, R.; Xu, Y.; Baek, K.; Dobrucki, L. W.; Fan, T. M.; Cheng, J. Drug-Initiated RingOpening Polymerization of O-Carboxyanhydrides for the Preparation of Anticancer Drug-Poly $(O$ carboxyanhydride) Nanoconjugates. Biomacromolecules 2013, 14, 920-929.

(2) Lu, Y.; Yin, L.; Zhang, Y.; Zhang, Z.; Xu, Y.; Tong, R.; Cheng, J. Synthesis of Water-Soluble Poly( $\alpha$-hydroxy acids) from Living Ring-Opening Polymerization of $O$-Benzyl-L-serine Carboxyanhydrides. ACS Macro Lett. 2012, 1, 441-444.

(3) Thillaye du Boullay, O.; Bonduelle, C.; Martin-Vaca, B.; Bourissou, D. Functionalized Polyesters from Organocatalyzed ROP of GluOCA, the $O$-carboxyanhydride Derived from Glutamic Acid. Chem. Commun. 2008, 1786-1788.

(4) Thillaye du Boullay, O.; Marchal, E.; Martin-Vaca, B.; Cossío, F. P.; Bourissou, D. An Activated Equivalent of Lactide toward Organocatalytic Ring-Opening Polymerization. J. Am. Chem. Soc. 2006, $128,16442-16443$.

(5) Buchard, A.; Carbery, D. R.; Davidson, M. G.; Ivanova, P. K.; Jeffery, B. J.; Kociok-Köhn, G. I.; Lowe, J. P. Preparation of Stereoregular Isotactic Poly(mandelic acid) through Organocatalytic RingOpening Polymerization of a Cyclic O-Carboxyanhydride. Angew. Chem. Int. Ed. 2014, 53, 13858-13861. (6) Lee, D.-Y.; Hartwig, J. F. Zinc Trimethylsilylamide as a Mild Ammonia Equivalent and Base for the Amination of Aryl Halides and Triflates. Org. Lett. 2005, 7, 1169-1172.

(7) (a) Williams, C. K.; Breyfogle, L. E.; Choi, S. K.; Nam, W.; Young, V. G.; Hillmyer, M. A.; Tolman, W. B. A Highly Active Zinc Catalyst for the Controlled Polymerization of Lactide. J. Am. Chem. Soc. 2003, 125, 11350-11359; (b) Darensbourg, D. J.; Karroonnirun, O. Ring-Opening Polymerization of LLactide and $\varepsilon$-Caprolactone Utilizing Biocompatible Zinc Catalysts. Random Copolymerization of LLactide and $\varepsilon$-Caprolactone. Macromolecules 2010, 43, 8880-8886.

(8) Chamberlain, B. M.; Cheng, M.; Moore, D. R.; Ovitt, T. M.; Lobkovsky, E. B.; Coates, G. W. Polymerization of Lactide with Zinc and Magnesium $\beta$-Diiminate Complexes: Stereocontrol and Mechanism. J. Am. Chem. Soc. 2001, 123, 3229-3238.

(9) Bryan, A. M.; Long, G. J.; Grandjean, F.; Power, P. P. Synthesis, Spectroscopic Characterization, and Determination of the Solution Association Energy of the Dimer $\left[\mathrm{Co}\left\{\mathrm{N}\left(\mathrm{SiMe}_{3}\right)_{2}\right\}_{2}\right]_{2}$ : Magnetic Studies of Low-Coordinate $\mathrm{Co}$ (II) Silylamides $\left[\mathrm{Co}\left\{\mathrm{N}\left(\mathrm{SiMe}_{3}\right)_{2}\right\}_{2} \mathrm{~L}\right]\left(\mathrm{L}=\mathrm{PMe}_{3}\right.$, Pyridine, and THF) and Related Species That Reveal Evidence of Very Large Zero-Field Splittings. Inorganic Chemistry 2013, 52, 12152-12160.

(10) (a) Wang, R.; Zhang, J.; Yin, Q.; Xu, Y.; Cheng, J.; Tong, R. Controlled Ring-Opening Polymerization of $O$-Carboxyanhydrides Using a $\beta$-Diiminate Zinc Catalyst. Angew. Chem. Int. Ed. 2016, 55, 13010-13014; (b) Feng, Q.; Tong, R. Controlled Photoredox Ring-Opening Polymerization of $O$ Carboxyanhydrides. J. Am. Chem. Soc. 2017, 139, 6177-6182.

(11) Gagne, R. R.; Koval, C. A.; Lisensky, G. C. Ferrocene as an Internal Standard for Electrochemical Measurements. Inorg. Chem. 1980, 19, 2854-2855.

(12) Pavlishchuk, V. V.; Addison, A. W. Conversion Constants for Redox Potentials Measured versus Different Reference Electrodes in Acetonitrile Solutions at $25^{\circ}$ C. Inorg. Chim. Acta 2000, 298, 97-102.

(13) Li, C.; Kawamata, Y.; Nakamura, H.; Vantourout, J. C.; Liu, Z.; Hou, Q.; Bao, D.; Starr, J. T.; Chen, J.; Yan, M.; Baran, P. S. Electrochemically Enabled, Nickel-Catalyzed Amination. Angew. Chem. Int. Ed. 2017, 56, 13088-13093.

(14) Feng, Q.; Yang, L.; Zhong, Y.; Guo, D.; Liu, G.; Xie, L.; Huang, W.; Tong, R. Stereoselective Photoredox Ring-Opening Polymerization of $O$-carboxyanhydrides. Nat. Commun. 2018, 9, 1559.

(15) (a) Deming, T. J. Transition Metal-Amine Initiators for Preparation of Well-Defined Poly ( $\gamma$-benzyl L-glutamate). J. Am. Chem. Soc. 1997, 119, 2759-2760; (b) Deming, T. J.; Curtin, S. A. Chain Initiation Efficiency in Cobalt- and Nickel-Mediated Polypeptide Synthesis. J. Am. Chem. Soc. 2000, 122, 57105717.

(16) (a) Anson, F. C.; Collins, T. J.; Coots, R. J.; Gipson, S. L.; Richmond, T. G. Synthesis and Characterization of Stable Cobalt(IV) Coordination Complexes: Molecular Structure of Trans-[.eta.4-1,2- 
bis(3,5-dichloro-2-hydroxybenzamido)-4,5-dichlorobenzene]bis(4-tert-butylpyridine)cobalt(IV). J. Am. Chem. Soc. 1984, 106, 5037-5038; (b) Wolberg, A.; Manassen, J. Electrochemical and Electron Paramagnetic Resonance Studies of Metalloporphyrins and their Electrochemical Oxidation Products. $J$. Am. Chem. Soc. 1970, 92, 2982-2991; (c) Srinivasan, S.; Annaraj, J.; Athappan, P. R. Spectral and Redox Studies on Mixed Ligand Complexes of Cobalt(III) Phenanthroline/bipyridyl and Benzoylhydrazones, their DNA Binding and Antimicrobial Activity. J. Inorg. Biochem. 2005, 99, 876-882; (d) Ferreira, H.; Conradie, M. M.; Conradie, J. Cyclic Voltammetry Data of Polypyridine Ligands and Co(II)-Polypyridine Complexes. Data in Brief 2019, 22, 436-445.

(17) Lu, H.; Dzik, W. I.; Xu, X.; Wojtas, L.; de Bruin, B.; Zhang, X. P. Experimental Evidence for Cobalt(III)-Carbene Radicals: Key Intermediates in Cobalt(II)-Based Metalloradical Cyclopropanation. $J$. Am. Chem. Soc. 2011, 133, 8518-8521.

(18) Randall, J. C. C-13 Nuclear Magnetic Resonance Quantative Measurements of Average Sequence Lengths of Like Stereochemical Additions in Polypropylene and Polystyrene. J. Polym. Sci., Part B: Polym. Lett. 1976, 14, 2083-2094. 